\title{
LncRNA ROR1-AS1 high expression and its prognostic significance in liver cancer
}

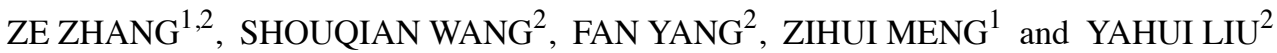 \\ ${ }^{1}$ Department of Hepatobiliary-Pancreatic Surgery, China-Japan Union Hospital of Jilin University, Changchun, Jilin 130000; \\ ${ }^{2}$ Department of General Surgery, The First Hospital of Jilin University, Changchun, Jilin 130021, P.R. China
}

Received July 16, 2019; Accepted September 27, 2019

DOI: $10.3892 /$ or.2019.7398

\begin{abstract}
Hepatocellular carcinoma (HCC) is a common disease of the digestive system with no curative treatments. Long noncoding RNA tyrosine protein kinase transmembrane receptor 1 antisense RNA 1 (IncRNA ROR1-AS1) is an IncRNA whose functions have been predicted in human diseases; however, its important role in cancer has been probed only in mantle cell lymphoma, not in HCC. Therefore, the present study aimed to elucidate the prognostic significance of lncRNA ROR1-AS1 in HCC. The Cancer Genome Atlas Liver Hepatocellular Carcinoma was used to analyze the expression of ROR1-AS1 in liver cancer. $\chi^{2}$ tests were performed to evaluate associations between clinical characteristics and ROR1-AS1 expression. The role of ROR1-AS1 in HCC prognosis was assessed using Kaplan-Meier curves and proportional hazards model (Cox) analysis. Gene set enrichment
\end{abstract}

Correspondence to: Dr Zihui Meng, Department of Hepatobiliary-Pancreatic Surgery, China-Japan Union Hospital of Jilin University, 126 Xiantai Street, Changchun, Jilin 130000, P.R. China

E-mail: zhmeng@jlu.edu.cn

Dr Yahui Liu, Department of General Surgery, The First Hospital of Jilin University, 71 Xinmin Street, Changchun, Jilin 130021, P.R. China

E-mail: liuyahui2018@yeah.net

Abbreviations: Cox, proportional hazards model; DAVID, Database for Annotation, Visualization, and Integrated Discovery; FDR, false discovery rate; GEO, Gene Expression Omnibus; GO, Gene Ontology; GSEA, gene set enrichment analysis; HCC, hepatocellular carcinoma; KEGG, Kyoto Encyclopedia of Genes and Genomes; KOBAS, KO-Based Annotation System; LncRNA, long noncoding RNA; MCL, mantle cell lymphoma; Mega, Molecular Evolutionary Genetics Analysis; MEM, Multi Experiment Matrix; OS, overall survival; ROC, receiver operating characteristic curve; ROR1-AS1, tyrosine protein kinase transmembrane receptor 1 antisense RNA 1; STRING, Search Tool for the Retrieval of Interacting Genes/Proteins; TCGA-LIHC, The Cancer Genome Atlas Liver Hepatocellular Carcinoma

Key words: liver cancer, lncRNA ROR1-AS1, prognosis, diagnosis analysis was performed by using a Gene Expression Omnibus dataset. At the same time, Multi Experiment Matrix was used to predict genes that may be co-expressed with ROR1-AS1. The Database for Annotation, Visualization and Integrated Discovery and KO-Based Annotation System were used to analyze the most closely associated cytological behaviors and pathways in HCC. Then, the genes in the three databases were integrated to screen mRNAs, microRNAs and lncRNAs that had co-expression relationships with ROR1-AS1. Cytoscape, Search Tool for the Retrieval of Interacting Genes/Proteins and Molecular Evolutionary Genetics Analysis were used to map potential regulatory networks and developmental relationships associated with ROR1-AS1. Finally, 12 genes most closely associated with ROR1-AS1 were identified, and their relationship was described using a Circos plot. The results showed that ROR1-AS1 was upregulated in HCC, and its expression was related to clinical stage, $\mathrm{T}$ stage and $\mathrm{N}$ stage. Furthermore, Kaplan-Meier curves and Cox analysis indicated that high expression of ROR1-AS1 was associated with poor prognosis, and that ROR1-AS1 was an independent risk factor for HCC. Co-expression data suggested that there may be a large regulatory network of 45 genes with indirect associations with ROR1-AS1, a small regulatory network of 15 genes with direct or indirect regulatory relationships, and a special regulatory network containing 12 genes directly associated with ROR1-AS1. The present findings indicated that high expression of ROR1-AS1 suggests poor prognosis in patients with HCC.

\section{Introduction}

Hepatocellular carcinoma (HCC) is a common and serious malignant tumor of the liver $(1,2)$. At present, surgical resection and standardized treatments are unable to reduce the high recurrence and metastasis rates of $\mathrm{HCC}$ (3). Thus, predicting the clinical outcomes of patients with HCC is challenging $(1,4)$. Numerous studies have verified the role of various histological parameters in predicting HCC prognosis (5-7); therefore, a novel cancer classification system which uses molecular markers to evaluate the prognosis of patients with HCC should be developed.

Long noncoding RNAs (lncRNAs) can significantly affect tumors via epigenetic regulation, transcription, mRNA expression and other aspects involved in tumor biological activity (8). They can interact with mRNAs or microRNAs (miRNAs/miRs) in human cancers, thereby affecting their 
expression. For example, lncRNA OIP5-antisense RNA (AS)1 interacts with miR-186a to inhibit zinc finger E-box binding homeobox 1 expression in HCC, adversely affecting the tumor cell metastasis (9). Additionally, lncRNA HOXA-AS2 regulates the NF- $\mathrm{KB}$ signaling activity to hinder endothelium inflammation (10). LncRNA ROR1-AS1 can regulate certain diseases and biological activities; for example, it can regulate the tumor development and cell proliferation of mantle cell lymphoma (MCL) (11). Recent studies have identified ROR1-AS1 as capable of indicating the novel progression stage of colorectal cancer as a biomarker $(12,13)$; however, whether it can indicate the progression of liver cancer as a specific marker requires further investigation.

The present study aimed to determine the prognostic significance of ROR1-AS1 in HCC. In this study, to assess the potential prognostic role of ROR1-AS1 in patients with HCC and evaluate the independent prognostic implication of its expression for the overall survival (OS) of patients, retrospective analysis was performed using tissue chip data and data from The Cancer Genome Atlas Liver Hepatocellular Carcinoma (TCGA-LIHC) cohort. Then, gene set enrichment analysis (GSEA) was conducted to acquire insight into the ROR1-AS1 regulatory system-associated biological functions and proteins. A total of 50 genes co-expressed with ROR1-AS1 were predicted using Multi Experiment Matrix (MEM). Using KO-Based Annotation System (KOBAS) and the Database for Annotation, Visualization and Integrated Discovery (DAVID), cytological pathways and behaviors with the closest association with HCC were determined. Subsequently, genes identified using the aforementioned three databases were integrated to screen for miRNAs, mRNAs and lncRNAs co-expressed with ROR1-AS1. Cytoscape, the Search Tool for the Retrieval of Interacting Genes/Proteins (STRING) and Molecular Evolutionary Genetics Analysis (Mega) were used to build potential regulatory networks, and evaluate the evolutionary development and genetic distance between the ROR1-AS1-associated genes in this network. Genes with the closest relationship with ROR1-AS1 were identified, and their association was described using a Circos plot. It was revealed that large (45 genes) and small (15 genes) regulatory networks associated with IncRNA ROR1-AS1 were identified in HCC, as well as a special regulatory network containing 12 genes.

\section{Materials and methods}

Data acquisition and collection. The data of patients with HCC mined from TCGA and RNA sequencing (RNA-seq) expression results were downloaded using the RTCGA Toolbox (version 3.5) package in $\mathrm{R}$ (version 3.5.3) $(14,15)$. Additionally, IncRNA ROR1-AS1 tumor expression data were obtained from TCGA for other digestive tumors, including bile duct, colon, esophagus, liver, pancreas and stomach. The gene microarray dataset GSE54236 $(16,17)$ was downloaded from the GEO database (https://www.ncbi.nlm.nih.gov/geo/) (18). The data used in this article were downloaded from the above databases in April 2019.

Statistical analyses. SPSS 23.0 software (IBM Corp.) was used for statistical analysis of data. Boxplots were used for discrete variables to measure differences in expression, and effects of clinicopathological characteristics on lncRNA ROR1-AS1 expression were analyzed using ANOVA; alterations in expression between each group were demonstrated using scatter plots (19). $\chi^{2}$ tests were used to examine the association between ROR1-AS1 expression and clinical data. GraphPad Prism 7.0 software (GraphPad Software, Inc.) was used to analyze the differential expression of ROR1-AS1 in different tumor tissues. Scatter plots and histograms were used for discrete variables to measure differences in expression between different tissues, and effects of tumor tissue of origin on IncRNA ROR1-AS1 expression were analyzed using the mean \pm SD (20). Correlation coefficient analyses were performed using R software (version 3.1.0) (21); a correlation coefficient $\mathrm{R}>0.5$ was considered to indicate a strong correlation. Receiver-operating characteristic curves (ROC) were drawn using the p-ROC package (version 1.0.3) to evaluate diagnostic ability (22); patients were divided into high and low ROR1-AS1 expression groups by using the median value of ROR1-AS1 expression as the optimal cutoff. Kaplan-Meier curves were used to compare differences in OS and relapse-free survival by using the survival package in R (23). Univariate proportional hazards model (Cox) analysis was used to select the related variables. Then, multivariate Cox analysis was applied to evaluate the influence of ROR1-AS1 expression on the OS and relapse-free survival of patients (24).

GSEA. GSEA is a computational method that determines whether an a priori defined set of genes shows statistically significant, concordant differences between two biological states. In this study, GSEA was performed by using the GSEA software 3.0 from the Broad Institute $(25,26)$. The gene expression data were RNA-seq data from TCGA-LIHC and GEO databases. The gene set of 'c2. cp.biocarta. v6.2.symbols.gmt', 'c3.cp.biocarta.v6.2.symbols.gmt', 'c5. cp.biocarta.v6.2.symbols. gmt' and 'h.all.v6.2.symbols.gmt', which summarizes and represents specific, well-defined biological states or processes, was downloaded from the Molecular Signatures Database (http://software.broadinstitute. org/gsea/msigdb/index.jsp) (27). The normalized enrichment score was acquired by analyzing with permutations for 1,000 times. A gene set is considered to be significantly enriched with normal $\mathrm{P}<0.05$ and false discovery rate $(\mathrm{FDR})<0.25$.

Gene enrichment and functional annotation evaluation. DAVID (http://david.abcc.ncifcrf.gov/), STRING (https:// string-db.org/) and KOBAS (http://kobas.cbi.pku.edu.cn/) were used to conduct relevant pathway analysis (28), including Gene Ontology (GO) term enrichment $(29,30)$, and Kyoto Encyclopedia of Genes and Genomes (KEGG) pathway analysis (31-33), which were performed for the functional annotation of the co-expressed genes (34). Three GO terms ('biological process', 'cellular component' and 'molecular function') were utilized to identify the enrichment of target genes. GO terms and KEGG pathways with $\mathrm{P}<0.05$ were considered statistically significant. The enrichment map of annotation analysis was drawn using Cytoscape version 3.3.1 (http://www.cytoscape.org/cy3.html) (35).

Prediction of related genes. MEM (https://biit.cs.ut.ee/mem/) contains a large collection of microarray datasets. Using 
simultaneous statistical significance estimation, MEM applies rank aggregation to merge information from different data sets into a single global ordering (36). In MEM, the output option for each probe was set to 1,694 , which were comprised 100 data sets, and the resulting similar genes were then exported. Genes that were present in at least two probe groups were selected. cBioPortal (http://www.cbioportal.org/index.do) incorporates data from 126 tumor genome research projects, including TCGA, International Cancer Genome Consortium and other large tumor research projects (35). The co-expression analysis module of MEM was used to extract genes that are co-expressed with IncRNA ROR1-AS1; co-expressed genes are defined as genes associated with ROR1-AS1 expression. The associated genes that were identified by MEM and data from GEO were subjected to gain Circos plots. Circos plots were generated based on the remappings of two tables from these two tools. Circos plots were generated using the Circos visualization tool in $\mathrm{R}$ (version 3.5.3) $(15,37,38)$.

Weighted gene co-expression network analysis (WGCNA). WGCNA (version 1.67) (34,39) (conducted using the WGCNA package in $\mathrm{R}$ ) elucidates the higher-order relationships between genes based on their co-expression relationships, delineating modules of biologically related genes and permitting a robust view of transcriptome organization (40). For WGCNA, the R package DCGL (version 2.1.2) (41) was used to filter genes; genes with FPKM values $>0.85$ were selected for further analysis. The adjacency matrix between different genes was constructed with 3 as the parameter of soft thresholding power to reduce noise and false correlation. A network was created from these data, first by calculating weighted Pearson correlation matrices corresponding to gene expression, then by following the standard procedure of WGCNA to create the holistic network. Briefly, weighted correlation matrices were transformed into matrices of connection strengths using a power function (34). These connection strengths were then used to calculate topological overlap, a robust and biologically meaningful measurement that encapsulates the three different genes' co-expression relationships in the network (42).

Mega. Phylogenetic Tree and Sequence Analysis Ago protein sequences were downloaded from the GenBank database of NONCODE (http://www.noncode.org/) and NCBI (https://www.ncbi.nlm.nih.gov/) (43). A multiple-sequence alignment was performed based on the PIWI domain using ClustalW software (version 2.1) (44). The phylogenetic tree was constructed using MEGA X (https://www.megasoftware. net/) based on the neighbor-joining method with a bootstrap value of 1,000 replicates (45).

Genome map. After integrating the gene expression data of patients with HCC from the three databases, the correlation coefficient between different genes and ROR1-AS1 was calculated (as described in the Statistical analyses section), and a Venn diagram was constructed in GraphPad Prism 7 using the calculated results (46) to validate the reliability of the results obtained via co-expression analysis. Alignments of gene co-expression maps to GRCh38.95 (reference genome version of Homo sapiens) (47) (ftp://ftp.ncbi.nlm.nih. gov/genomes/all/GCA_000001405.15_GRCh38.95) identified
Table I. Demographic and clinical characteristics of TCGA-LIHC cohort $(n=300)$.

\begin{tabular}{|c|c|c|}
\hline Characteristics & Number & Percentage $(\%)$ \\
\hline \multicolumn{3}{|l|}{ Age (years) } \\
\hline$\leq 55$ & 105 & 35.00 \\
\hline$>55$ & 195 & 65.00 \\
\hline \multicolumn{3}{|l|}{ Gender } \\
\hline Female & 90 & 30.00 \\
\hline Male & 210 & 70.00 \\
\hline \multicolumn{3}{|l|}{ T stage } \\
\hline $\mathrm{T} 1$ & 151 & 50.34 \\
\hline $\mathrm{T} 2$ & 75 & 25.00 \\
\hline $\mathrm{T} 3$ & 63 & 21.00 \\
\hline $\mathrm{T} 4$ & 10 & 3.33 \\
\hline Unknown & 1 & 0.33 \\
\hline \multicolumn{3}{|l|}{ M stage } \\
\hline M0 & 227 & 75.67 \\
\hline M1 & 2 & 0.66 \\
\hline $\mathrm{Mx}$ & 71 & 23.67 \\
\hline \multicolumn{3}{|l|}{$\mathrm{N}$ stage } \\
\hline No & 217 & 72.33 \\
\hline N1 & 3 & 0.99 \\
\hline $\mathrm{Nx}$ & 80 & 26.67 \\
\hline \multicolumn{3}{|l|}{ Stage } \\
\hline I & 151 & 50.34 \\
\hline II & 73 & 24.33 \\
\hline III & 72 & 24.00 \\
\hline IV & 4 & 1.33 \\
\hline \multicolumn{3}{|l|}{ Histologic grade } \\
\hline G1 & 42 & 14.00 \\
\hline G2 & 145 & 48.33 \\
\hline G3 & 101 & 33.67 \\
\hline G4 & 12 & 4.00 \\
\hline \multicolumn{3}{|l|}{ Vital status } \\
\hline Survival & 217 & 72.33 \\
\hline Death & 83 & 27.67 \\
\hline \multicolumn{3}{|l|}{ Race } \\
\hline Asian & 148 & 49.33 \\
\hline Of African descent & 8 & 2.67 \\
\hline Caucasian & 138 & 46.00 \\
\hline Unknown & 6 & 2.00 \\
\hline \multicolumn{3}{|l|}{ ROR1-AS1 expression } \\
\hline High expression & 219 & 73.00 \\
\hline Low expression & 81 & 27.00 \\
\hline Total & 300 & 100.0 \\
\hline
\end{tabular}

TCGA, The Cancer Genome Atlas; LIHC, Liver Hepatocellular Carcinoma; ROR1-AS1, tyrosine protein kinase transmembrane receptor 1 antisense RNA 1.

reference genomic regions contributing to the composition of 12 genome sets (the location of the genes of interest in the human reference genome). In order to find the most represented 

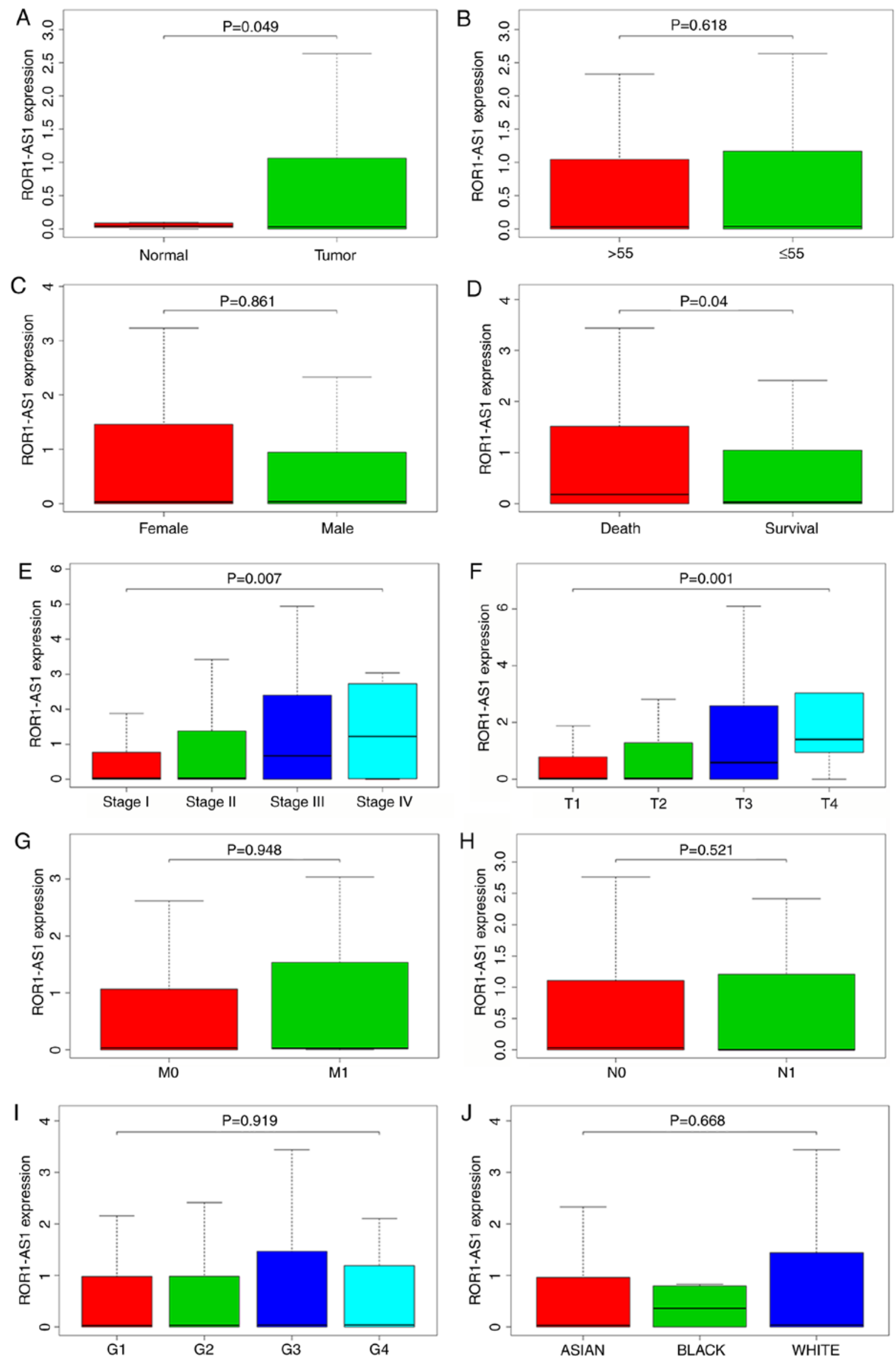

Figure 1. Effects of clinicopathological characteristics on lncRNA ROR1-AS1 expression. Boxplots showing differences in ROR1-AS1 expression according to (A) tissue type, (B) patient age, (C) gender, (D) survival status, (E) clinical stage, (F-H) TNM stage, (I) pathological status and (J) race. ROR1-AS1, tyrosine protein kinase transmembrane receptor 1 antisense RNA. 
A
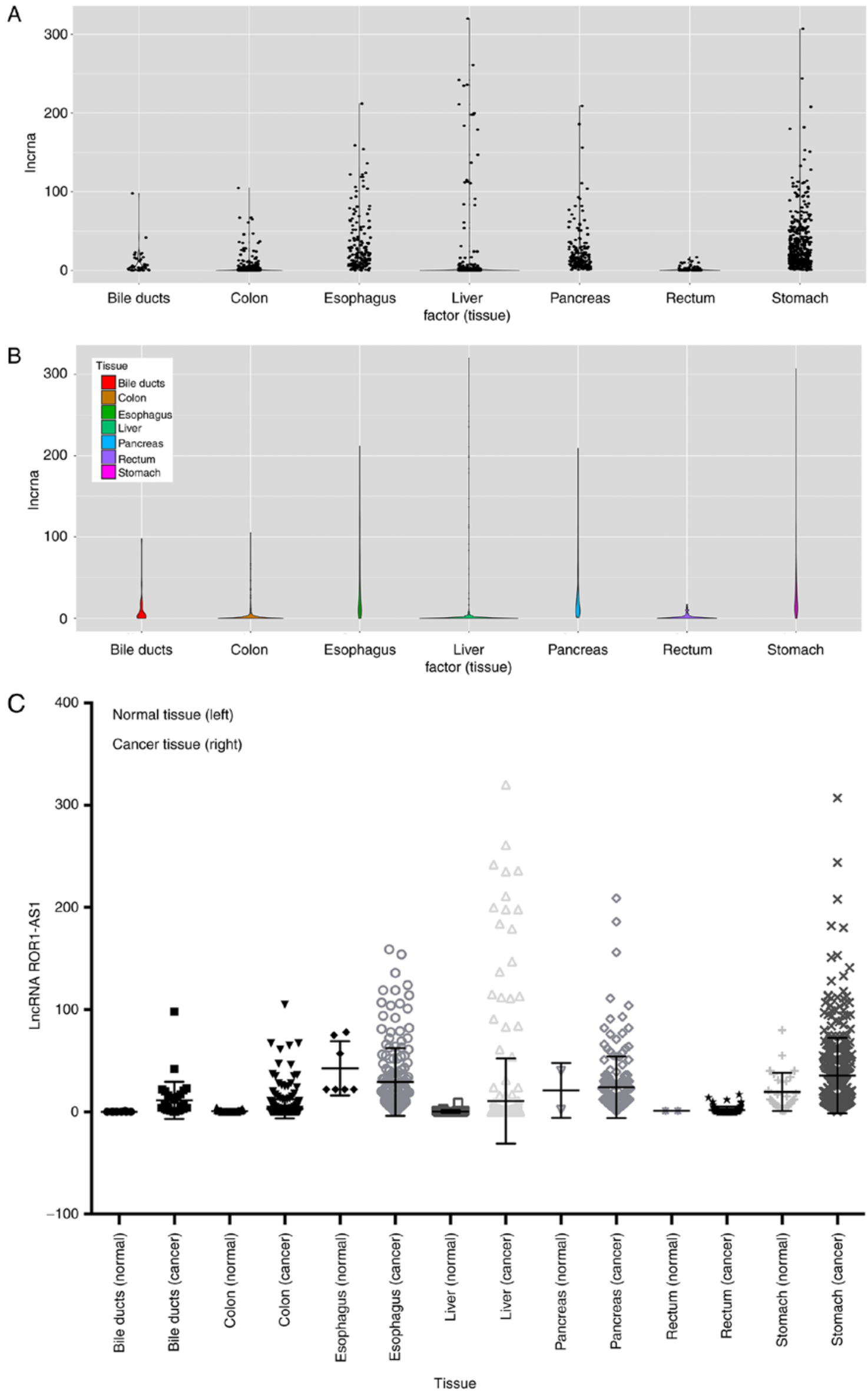

Figure 2. Long noncoding RNA ROR1-AS1 expression in common digestive system tumors based on The Cancer Genome Atlas database. (A) Scatter plot and (B) Violin map suggest that the ROR1-AS1 reveals a high expression state in HCC. (C) Expression levels of ROR1-AS1 in tumors were upregulated compared with normal tissues, excluding esophageal cancer. ROR1-AS1, tyrosine protein kinase transmembrane receptor 1 antisense RNA. 
Table II. Associations between lncRNA ROR1-AS 1 expression in hepatocellular carcinoma tissue and clinicopathologic variables.

\begin{tabular}{|c|c|c|c|c|c|c|}
\hline \multirow[b]{2}{*}{ Clinical characteristics } & \multirow[b]{2}{*}{ Variables } & \multirow[b]{2}{*}{ Number of patients } & \multicolumn{2}{|c|}{$\begin{array}{l}\text { LncRNA } \\
\text { ROR1-AS1 } \\
\text { expression }\end{array}$} & \multirow[b]{2}{*}{$\chi^{2}$} & \multirow[b]{2}{*}{ P-value } \\
\hline & & & High & Low & & \\
\hline \multirow{2}{*}{ Age (years) } & $\leq 55$ & 105 & 45 & 60 & 3.297 & 0.069 \\
\hline & $>55$ & 195 & 105 & 90 & & \\
\hline \multirow[t]{2}{*}{ Gender } & Female & 90 & 45 & 45 & 0.000 & $>0.999$ \\
\hline & Male & 210 & 105 & 105 & & \\
\hline \multirow[t]{2}{*}{ Grade } & $\mathrm{G} 1 / 2$ & 187 & 92 & 95 & 0.128 & 0.721 \\
\hline & $\mathrm{G} 3 / 4$ & 113 & 58 & 55 & & \\
\hline \multirow[t]{2}{*}{ Stage } & Stage I/II & 262 & 122 & 140 & 9.763 & $0.002^{\mathrm{a}}$ \\
\hline & Stage III/IV & 38 & 28 & 10 & & \\
\hline \multirow[t]{2}{*}{ T stage } & $\mathrm{T} 1 / 2$ & 227 & 100 & 127 & 13.198 & $<0.001^{\mathrm{a}}$ \\
\hline & $\mathrm{T} 3 / 4$ & 73 & 50 & 23 & & \\
\hline \multirow[t]{3}{*}{ M stage } & M0 & 227 & 113 & 114 & 0.001 & 0.995 \\
\hline & M1 & 2 & 1 & 1 & & \\
\hline & Mx (Not included) & 71 & 36 & 35 & & \\
\hline \multirow[t]{3}{*}{$\mathrm{N}$ stage } & No & 217 & 103 & 114 & 3.887 & $0.049^{\mathrm{a}}$ \\
\hline & N1 & 3 & 2 & 1 & & \\
\hline & Nx (Not included) & 80 & 47 & 35 & & \\
\hline \multirow[t]{2}{*}{ Vital status } & Survival & 217 & 103 & 114 & 2.015 & 0.156 \\
\hline & Death & 83 & 47 & 36 & & \\
\hline \multirow[t]{4}{*}{ Race } & Asian & 148 & 72 & 76 & 4.144 & 0.126 \\
\hline & Of African descent & 8 & 5 & 3 & & \\
\hline & Caucasian & 138 & 71 & 67 & & \\
\hline & Unknown (not included) & 6 & $\mathrm{~N} / \mathrm{A}$ & N/A & & \\
\hline
\end{tabular}

${ }^{\text {a}} \mathrm{P}<0.05$. LncRNA ROR1-AS1, long noncoding RNA tyrosine protein kinase transmembrane receptor 1 antisense RNA 1.

reference fragments, all GRCh38.95 loci present in the gene co-expression maps were deduced and merged, resulting in 12 reference donor fragments, which settled in the outermost track. The number of gene-regulated maps containing each of these fragment labels were then marked in the second track, excluding duplicate counts. In the inner sector, pairs of gene sets that exhibited regulation relationships were linked. The sum of the genome map alignments across the whole genome was used to link the 12 gene regulatory maps in the Circos plot.

\section{Results}

Patients' characteristics. Both gene expression and clinical data of patients with liver cancer were downloaded from TCGA database. The total number of patients was 427 . After the initial screening, 13 normal samples and 77 tumor samples without a specific lncRNA record or too much unclear information were removed, and the remaining 300 tumor samples and 37 normal samples were included. The detailed clinical characteristics are presented in Table I, including age, gender, TNM stage, survival status, pathological status and ethnic compositions.

High ROR1-AS1 expression in HCC. Using boxplots, the differences in ROR1-AS1 expression in patients with liver cancer and healthy individuals were ascertained. As presented in Fig. 1, the overall expression trend of ROR1-AS1 in liver cancer was evaluated, and it was found that ROR1-AS1 expression was significantly higher in primary HCC tissues compared with in normal liver tissues ( $\mathrm{P}=0.049$; Fig. 1A). Moreover, there were also differences in ROR1-AS1 expression based on vital status $(\mathrm{P}=0.040$; Fig. 1D), clinical stage $(\mathrm{P}=0.007$; Fig. 1E) and $\mathrm{T}$ stage $(\mathrm{P}=0.001$; Fig. $1 \mathrm{~F})$. No significant differences in ROR1-AS1 expression were observed based on patient age and the N\&M stage, gender, race and clinicopathological parameters (Fig. 1). Data on ROR1-AS1 expression in several common digestive tumors were also collected based on TCGA database (Fig. 2A and B). After horizontal comparison, it was found that except for esophageal cancer, ROR1-AS1 expression was upregulated in most digestive system tumors (Fig. 2C). This was clearer for liver, pancreatic and stomach cancer.

Relationship between ROR1-AS1 expression and clinical features in HCC. Using $\chi^{2}$ tests, associations between clinicopathological features and ROR1-AS1 expression were evaluated, as presented in Table II. ROR1-AS1 expression was significantly associated with clinical stage $\left(\chi^{2}=9.763, \mathrm{P}=0.002\right)$, T stage $\left(\chi^{2}=13.198, \mathrm{P}<0.001\right)$ and $\mathrm{N}$ stage $\left(\chi^{2}=3.887, \mathrm{P}=0.049\right)$.

High RORl-ASl expression as an independent prognostic factor for poor survival. Kaplan-Meier curves of OS were 
A

Kaplan-Meier curves for LIHC
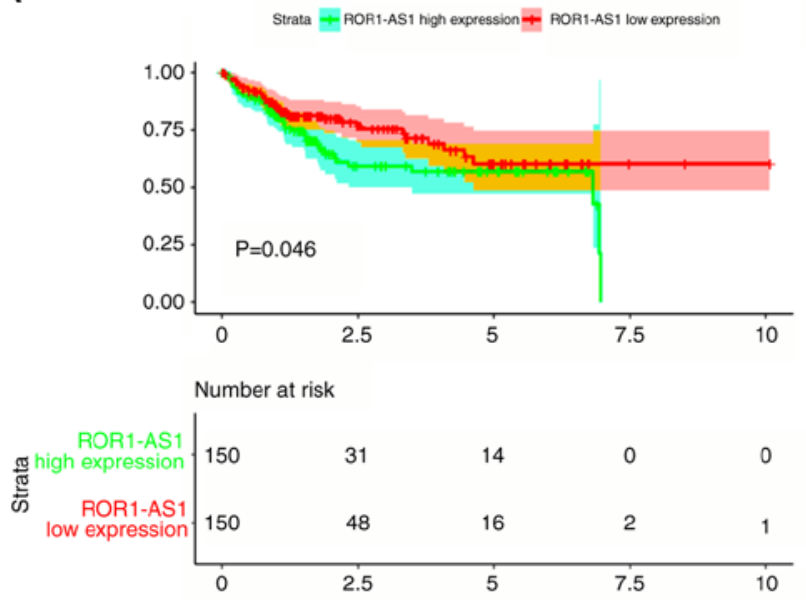

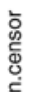

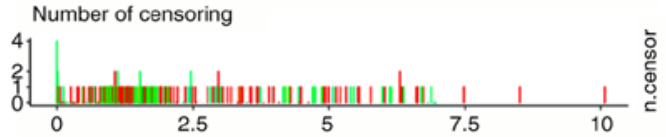

C

$$
\text { Advanced stage }
$$
Strata $=$ ROR1.AS1 high expression= ROR1.AS1 low expression
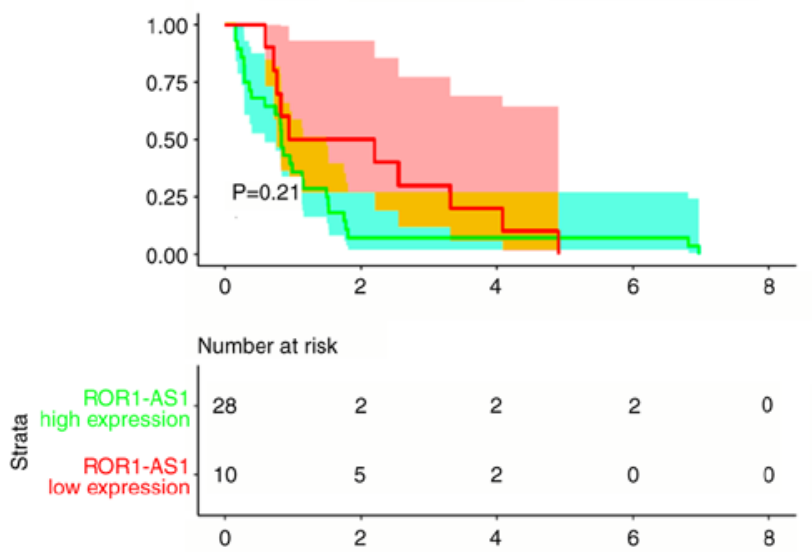

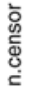

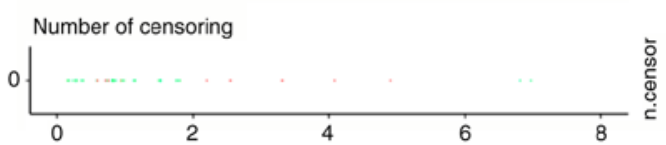

B
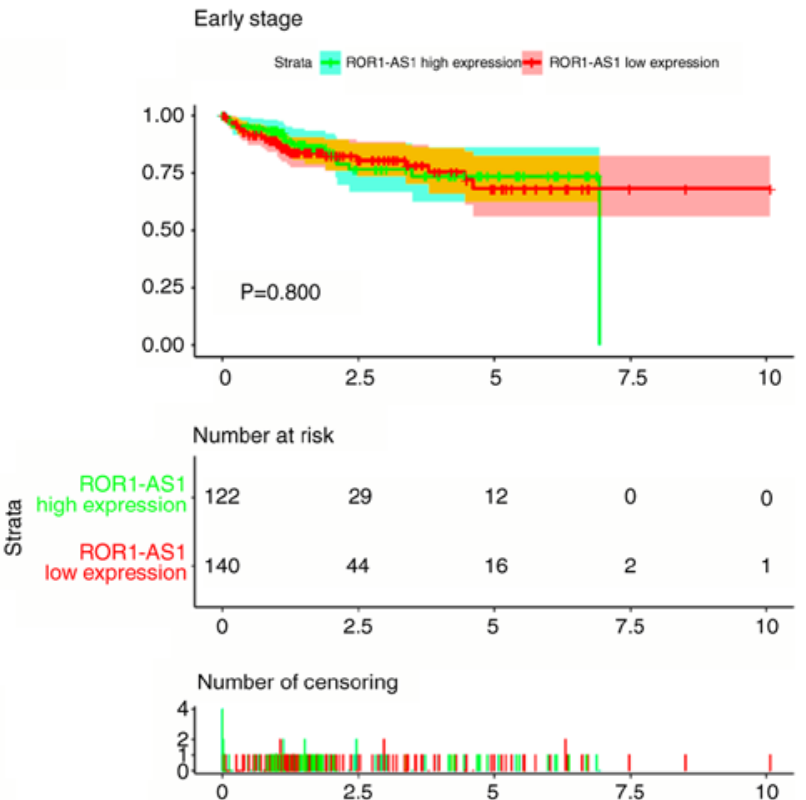

D
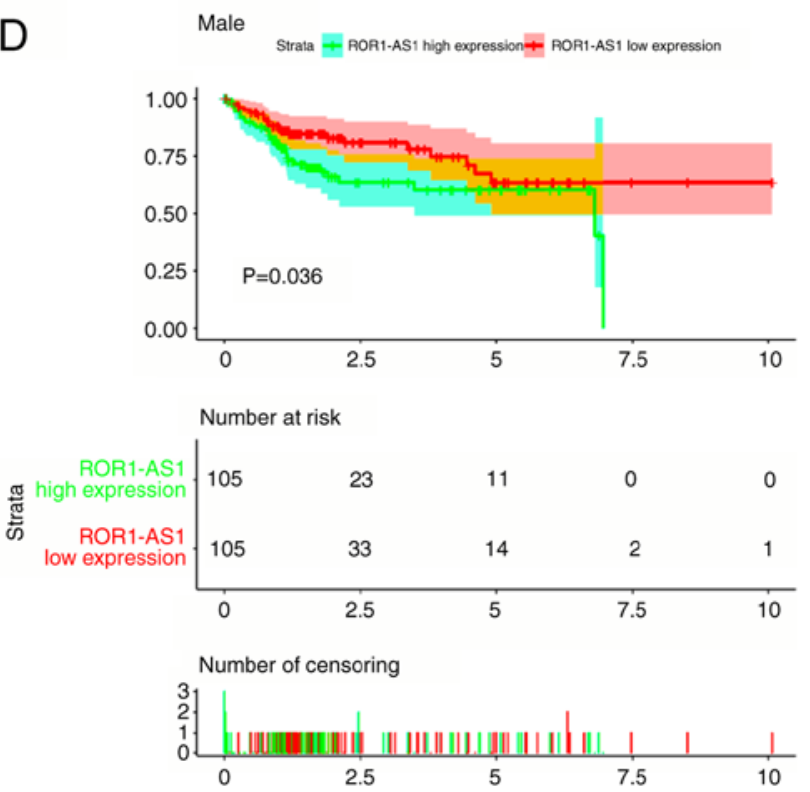

Figure 3. Kaplan-Meier curves for survival of patients with HCC according to ROR1-AS1 expression in HCC tissues. Green and red curves denote ROR1-AS1 high- and low-expression groups respectively. The ordinal (y-axis) indicates the percentage of survival, the abscissa (x-axis) represents survival years, and the number of survivors at the corresponding time. Censoring samples are shown as ' + ' marks. Kaplan-Meier curves and performance of stratification analysis by (A) overall expression, (B) early clinical stage and (C) advanced clinical stage, expression in (D) males and (E) females, expression in patients with (F) early T stage and (G) advanced T stage, (H) M0 stage, (I) N0 stage, patients aged (J) $\leq 55$ and (K) $>55$ years, according to (L) early pathological status and (M) advanced pathological status, and in patients from $(\mathrm{N})$ Asian and $(\mathrm{O})$ other races. ROR1-AS1, tyrosine protein kinase transmembrane receptor 1 antisense RNA.

plotted, and log-rank tests revealed that high ROR1-AS1 expression was associated with poor OS ( $\mathrm{P}=0.046$; Fig. $3 \mathrm{~A})$. Further subgroup analysis showed that ROR1-AS1 high expression was associated with poor $\mathrm{OS}$ in male patients $(\mathrm{P}=0.036$; Fig. $3 \mathrm{D})$, and patients at advanced $\mathrm{T}$ stage $(\mathrm{T} 3 / 4 ; \mathrm{P}=0.040 ;$ Fig. $3 \mathrm{G})$, N0 stage $(\mathrm{P}=0.0097$; Fig. 3I $)$, age $\leq 55(\mathrm{P}=0.044$; Fig. 3J $)$ and early pathological stage $(\mathrm{G} 1 / 2 ; \mathrm{P}=0.044$; Fig. 3L), and of Other race (Of African Descent and Caucasian) $(\mathrm{P}=0.049$; Fig. 3O). As presented in Fig. 4, ROC analysis of ROR1-AS1 was performed, and the area under the curve value was 0.59 , indicating moderate diagnostic ability. In patients with high ROR1-AS1 expression, critical variables (age, gender, clinical stage, pathological grade and TMN classification) were selected by univariate analysis. Multivariate analysis with the Cox proportional hazards model indicated that $\mathrm{T}$ classification $(\mathrm{HR}=2.258, \mathrm{P}=0.039), \mathrm{M}$ classification $(\mathrm{HR}=2.450, \mathrm{P}=0.011)$ and $\mathrm{N}$ classification $(\mathrm{HR}=1.724, \mathrm{P}<0.001)$ were independent prognostic factors for patients with HCC (Table III).

GSEA identifies ROR1-AS1-related biological functions and proteins. To identify biological functions activated in liver cancer, data from 161 tissue chips in the GEO database were screened (GSE54236; Fig. S1). GSEA between high and low ROR1-AS1 expression data sets was conducted. GSEA revealed significant differences (FDR $<0.25, \mathrm{P}<0.05)$ in the enrichment of 'MSigDB Collection', and the specific contents 
$\mathrm{E}$
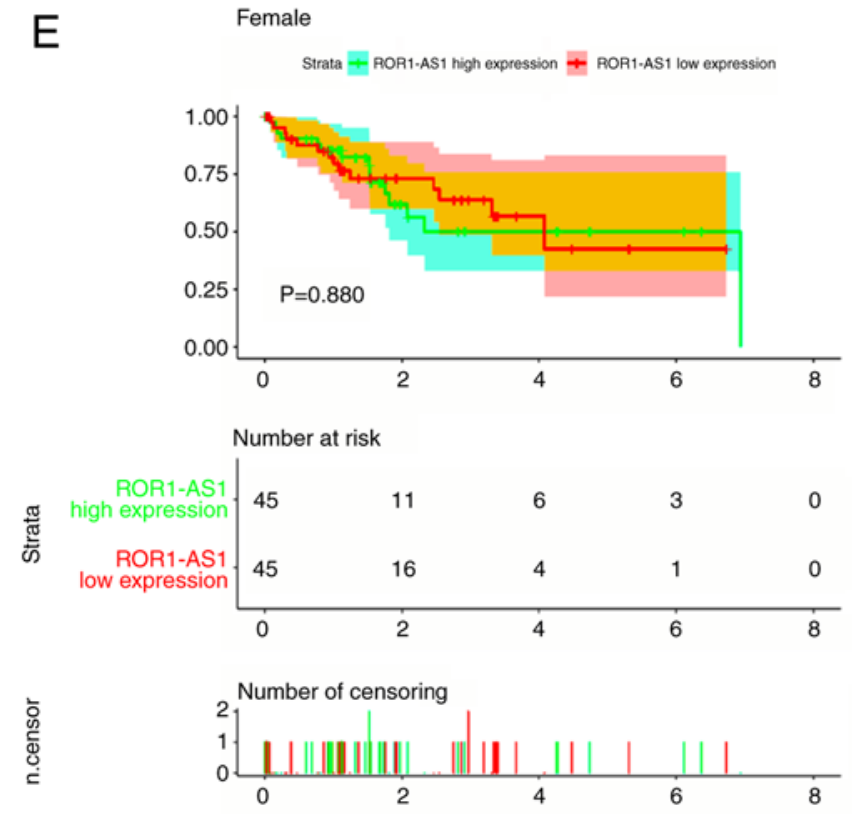

G

$$
\text { T3\&T4 }
$$

Strata + ROR1-AS1 high expression + ROR1-AS1 low expression
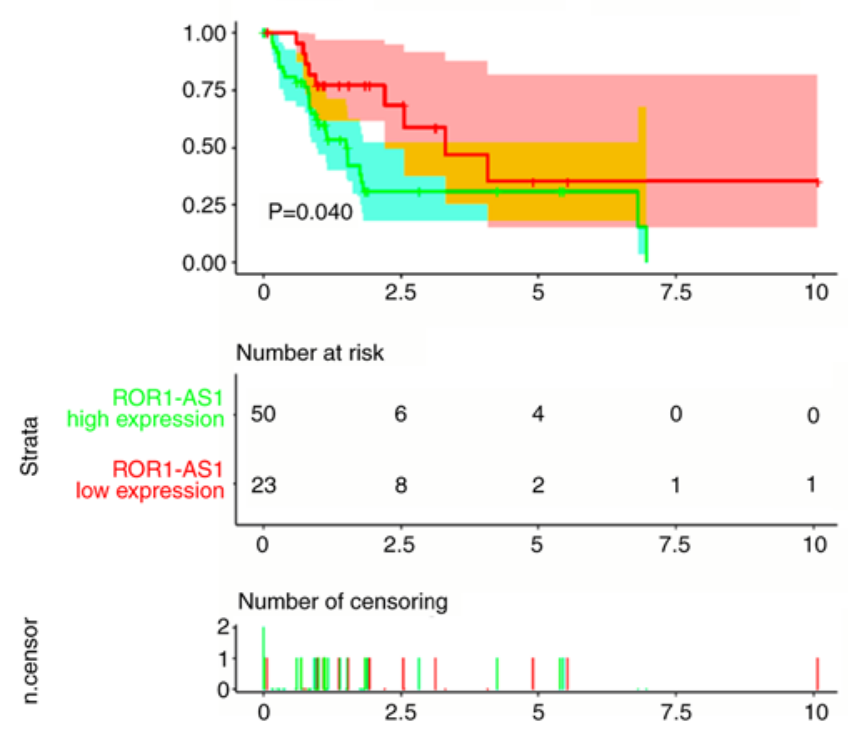

$\mathrm{F}$

T1\&T2
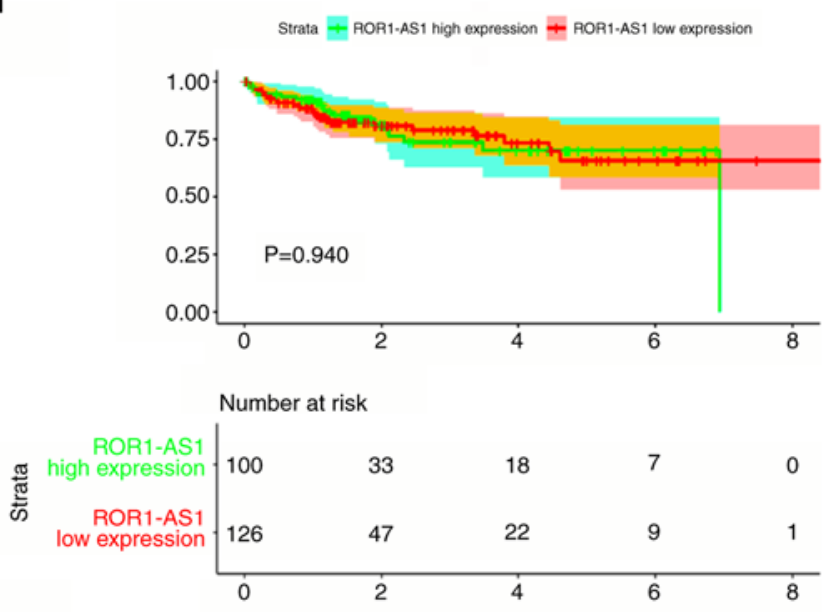

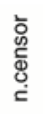

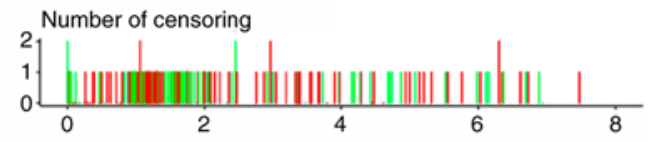

$\mathrm{H}$

Mo

Strata $=$ ROR1-AS1 high expression $=$ ROR1-AS1 low expression

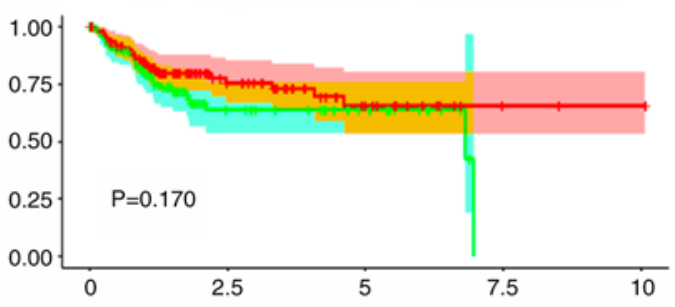

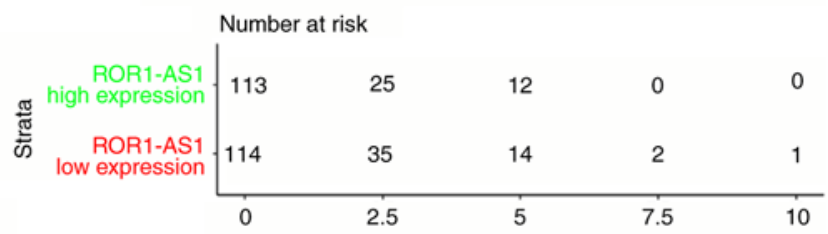

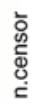

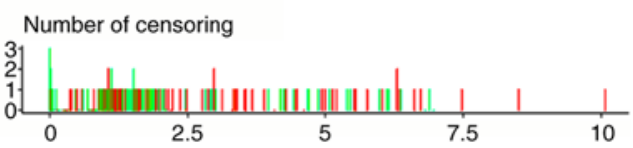

Figure 3. Continued. Kaplan-Meier curves for survival of patients with HCC according to ROR1-AS1 expression in HCC tissues. Green and red curves denote ROR1-AS1 high- and low-expression groups respectively. The ordinal (y-axis) indicates the percentage of survival, the abscissa (x-axis) represents survival years, and the number of survivors at the corresponding time. Censoring samples are shown as ' + ' marks. Kaplan-Meier curves and performance of stratification analysis by (A) overall expression, (B) early clinical stage and (C) advanced clinical stage, expression in (D) males and (E) females, expression in patients with (F) early T stage and $(\mathrm{G})$ advanced T stage, $(\mathrm{H}) \mathrm{M} 0$ stage, (I) N0 stage, patients aged $(\mathrm{J}) \leq 55$ and $(\mathrm{K})>55$ years, according to (L) early pathological status and (M) advanced pathological status, and in patients from $(\mathrm{N})$ Asian and (O) other races. ROR1-AS1, tyrosine protein kinase transmembrane receptor 1 antisense RNA.

are presented in Tables IV and V. In HCC, the expression profiles of patients with high ROR1-AS1 expression were significantly enriched with the following GO terms: Cytosolic ribosome, cell substrate junction, integrin binding, positive regulation of Wnt signaling pathway, regulation of establishment of planar polarity, negative regulation of development, nonmotile primary cilium assembly, protein kinase A catalytic subunit binding and signal transduction in absence of ligand (Table IV). Analysis of TCGA data revealed a significant positive effect of tumor grade and clinical stage on ROR1-AS1 expression (Fig. 1E and F), and there was a positive regulatory relationship between the expression levels of epidermal growth factor receptor, placental growth factor, leukotriene
E2 and ERB2 (Table V). Conversely, a negative regulatory relationship was identified between the expression levels of ROR1-AS1, and those of P53, JNK and Janus kinase 2. Meanwhile, the expression levels of E2F1, lymphoid enhancer binding factor 1 , mTOR, activating transcription factor $2, \mathrm{RAF}$ and downstream signaling pathways activated by cAMP were only initially positively associated with elevated expression of ROR1-AS1; as ROR1-AS1 continued to increased, these genes exhibited a negative expression relationship (Table V).

Prediction of related genes, and gene enrichment and functional annotation analyses. A total of 100 datasets including 1,694 samples were used to analyze the genes co-expressed with 
I

No

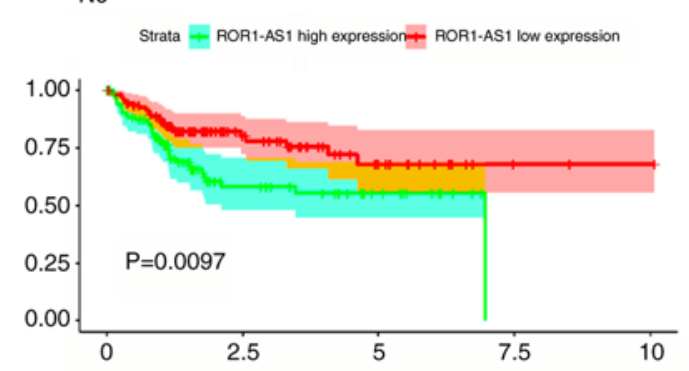

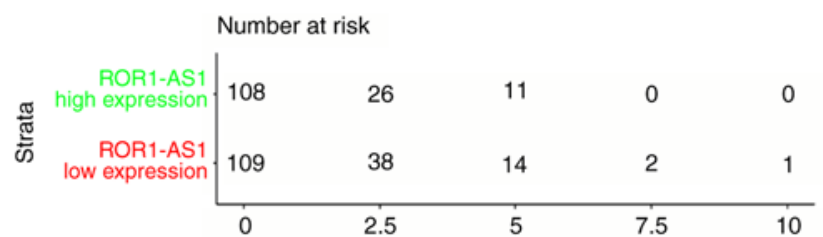

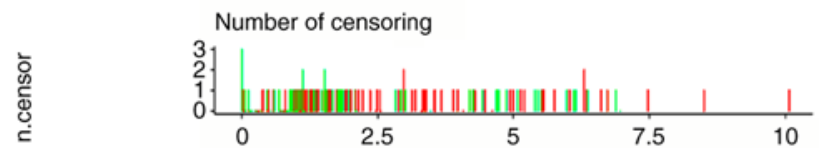

Age $>55$

$\mathrm{K}$
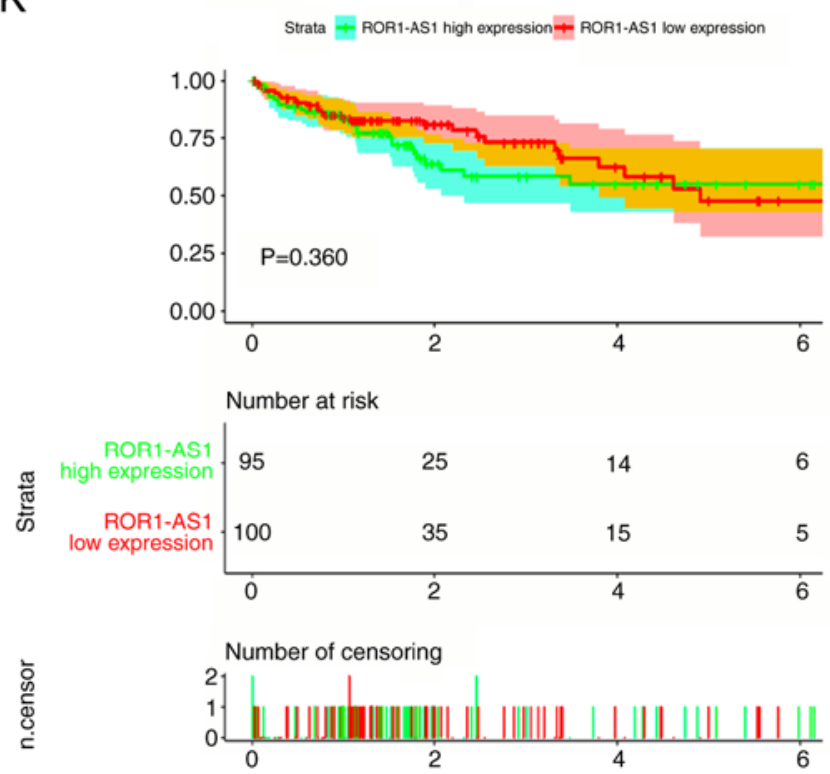

J
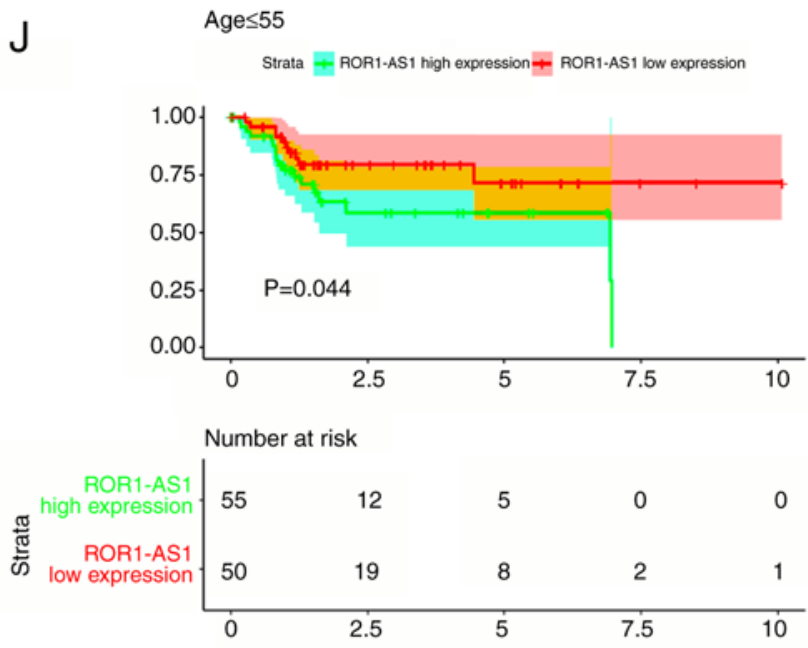

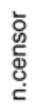

$\mathrm{L}$

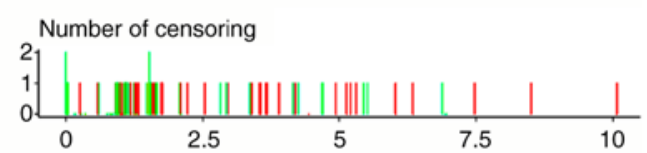

G1\&G2
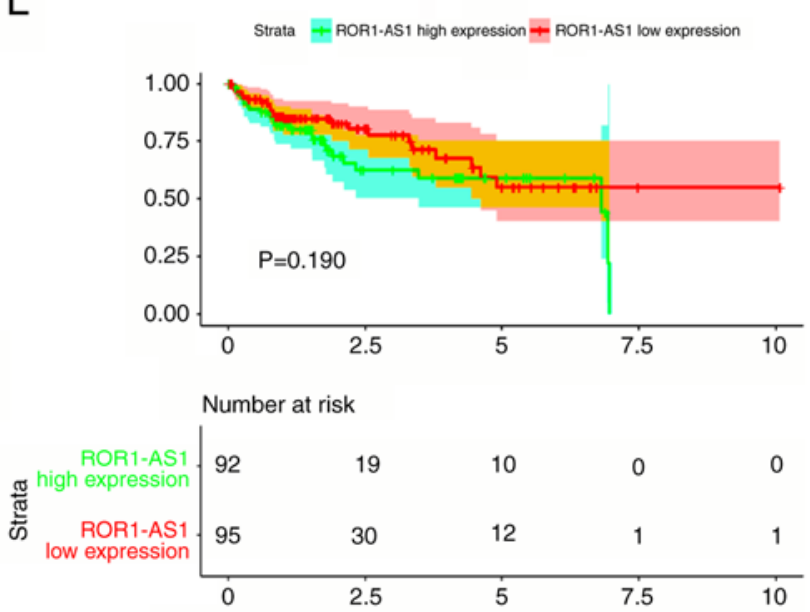

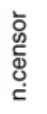

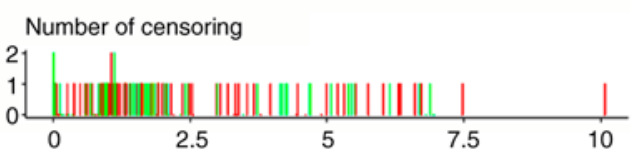

Figure 3. Continued. Kaplan-Meier curves for survival of patients with HCC according to ROR1-AS1 expression in HCC tissues. Green and red curves denote ROR1-AS1 high- and low-expression groups respectively. The ordinal (y-axis) indicates the percentage of survival, the abscissa (x-axis) represents survival years, and the number of survivors at the corresponding time. Censoring samples are shown as '+' marks. Kaplan-Meier curves and performance of stratification analysis by (A) overall expression, (B) early clinical stage and (C) advanced clinical stage, expression in (D) males and (E) females, expression in patients with (F) early T stage and (G) advanced T stage, (H) M0 stage, (I) N0 stage, patients aged (J) $\leq 55$ and (K) $>55$ years, according to (L) early pathological status and (M) advanced pathological status, and in patients from (N) Asian and (O) other races. ROR1-AS1, tyrosine protein kinase transmembrane receptor 1 antisense RNA.

ROR1-AS1 in MEM. In Fig. 5, only samples with liver tissue as the research background were selected, and 40 genes most closely associated with ROR1-AS1 were listed. The significant GO terms and KEGG pathways were identified by KOBAS and DAVID. First, STRING was used to enrich the functional protein association network. After removing nodes without additional links, it was found that there may be certain small regulatory networks within the whole system (Fig. S2). Then, R was used to determine these enriched GO terms (Fig. 6) and KEGG pathways (Fig. 7). To conduct a visual enrichment analysis of genes enriched in the GO pathways and build an interaction network for related genes, Cytoscape was used. The results in Table VI revealed that the target genes were most highly enriched in the following GO terms: Calcium ion binding, extracellular region, metalloendopeptidase activity, extracellular space, extracellular matrix binding and defense response to fungus (Fig. 6), and through the following KEGG pathways: Thyroid hormone signaling pathway, Rap1 signaling pathway, regulation of actin cytoskeleton, Pi3K-Akt signaling pathway, neuroactive ligand-receptor interaction and metabolic related pathways (Fig. 7).

Co-expression network construction. To further analyze the important biological role of ROR1-AS1 in HCC, co-expression analysis was conducted on the data from GSE54236. Next, the co-expressed genes identified in GEO were comprehensively 
M

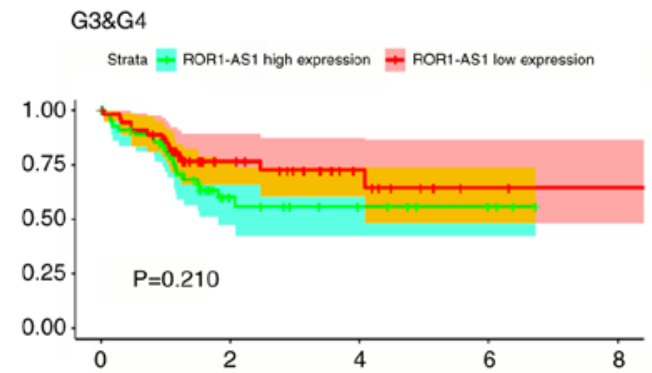

$\mathrm{N}$

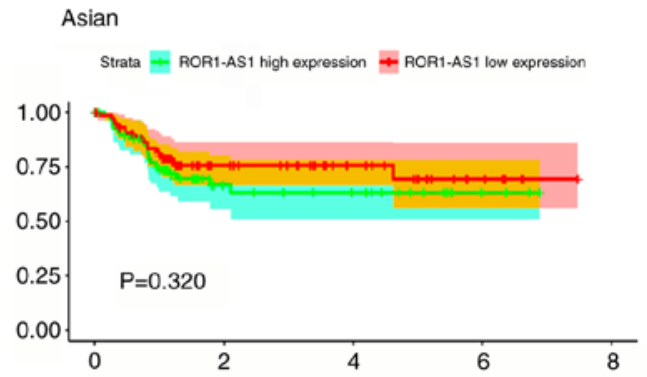

Number at risk

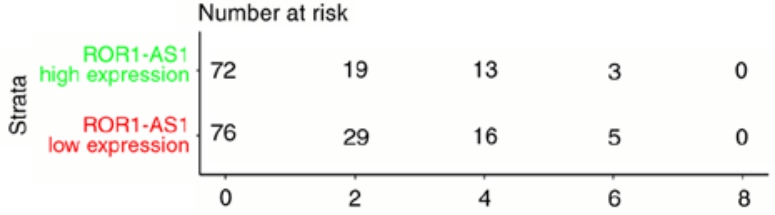

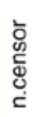

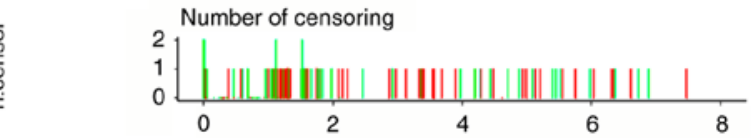

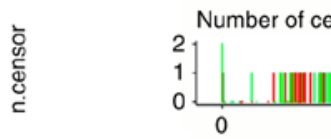

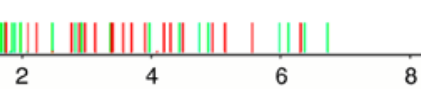

Other race
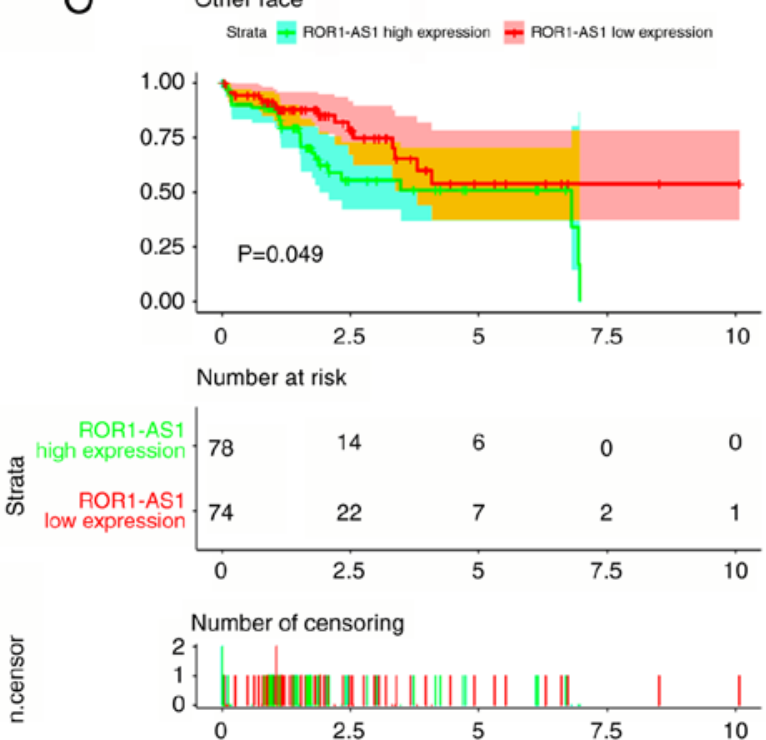

Figure 3. Continued. Kaplan-Meier curves for survival of patients with HCC according to ROR1-AS1 expression in HCC tissues. Green and red curves denote ROR1-AS1 high- and low-expression groups respectively. The ordinal (y-axis) indicates the percentage of survival, the abscissa (x-axis) represents survival years, and the number of survivors at the corresponding time. Censoring samples are shown as '+' marks. Kaplan-Meier curves and performance of stratification analysis by (A) overall expression, (B) early clinical stage and (C) advanced clinical stage, expression in (D) males and (E) females, expression in patients with (F) early T stage and (G) advanced T stage, (H) M0 stage, (I) N0 stage, patients aged (J) $\leq 55$ and (K) $>55$ years, according to (L) early pathological status and (M) advanced pathological status, and in patients from $(\mathrm{N})$ Asian and $(\mathrm{O})$ other races. ROR1-AS1, tyrosine protein kinase transmembrane receptor 1 antisense RNA.

analyzed using the gene matrix recorded in TCGA-LIHC. The WGCNA package in $\mathrm{R}$ was employed to analyze the relationship between lncRNAs and miRNAs (power value=3), and the relationship between miRNAs and mRNAs (power value=2). Subsequently, genes associated with ROR1-AS1 were selected for the co-expression grid (Fig. S3). Cytoscape was used to identify potential co-expression regulatory networks, revealing that based on these co-expressed genes, there may be a large regulatory network containing 45 genes and a small regulatory network containing 15 genes (Fig. 8). Notably, 10 pairs of genes were found to exhibit direct regulatory interactions with ROR1-AS1 (highlighted with red lines; Fig. 8).

Phylogenetic tree and Co-expressed genome maps. In Fig. 9, the spatial structure of ROR1-AS1 and its transcript information in the NONCODE database is presented. A phylogenetic tree was constructed using 23 genes collected from the NCBI and NONCODE databases for which there is clear transcript information for homo sapiens (Fig. 9). The phylogenetic tree showed that these co-expressed genes were split into 4 subfamilies; chromosome 1 open reading frame 94 (Clorf94), olfactomedin-like 2b (OLFML2B), caytaxin (ATCAY), troponin T3(TNNT3), PAX7 and fatty acid-binding protein 7 (FABP7) were located in the same subfamily as ROR1-AS1 (Fig. S4). Based on the co-expression network presented in Fig. 8, the degree of relevance of the 15 genes contained in the small regulatory network was analyzed. Excluding genes with $\mathrm{R}<0.5$, only 12 genes with $\mathrm{R}$ values $>0.5$ were maintained and then verified in three databases (Fig. 10).

Alignments of gene co-expression maps to GRCh38.95 identified reference genomic regions contributing to the 
Table III. Univariate and multivariate analyses of high lncRNA ROR1-AS1 expression in patients with liver cancer.

\begin{tabular}{|c|c|c|c|c|c|c|}
\hline \multirow[b]{2}{*}{ Parameters } & \multicolumn{3}{|c|}{ Univariate analysis } & \multicolumn{3}{|c|}{ Multivariate analysis } \\
\hline & HR & $95 \% \mathrm{CI}$ & P-value & HR & $95 \% \mathrm{CI}$ & P-value \\
\hline Age, years ( $\leq 55$ vs. $>55)$ & 1.022 & 0.994-1.05 & 0.132 & & & \\
\hline Gender (female vs. male) & 1.002 & $0.517-1.943$ & 0.995 & & & \\
\hline Race (Asian vs. of African descent vs. Caucasian) & 0.669 & $0.432-1.038$ & 0.073 & & & \\
\hline Grade (G1 vs. G2 vs. G3 vs. G4) & 0.868 & $0.561-1.343$ & 0.524 & 0.899 & $0.815-1.129$ & 0.736 \\
\hline Stage (Stage I vs. II vs. III vs. IV) & 0.804 & $0.259-2.492$ & 0.705 & 0.935 & $0.472-2.247$ & 0.638 \\
\hline T stage (T1 vs. T2 vs. T3 vs. T4) & 2.899 & $1.039-8.095$ & $0.042^{\mathrm{a}}$ & 2.258 & $1.638-3.113$ & $0.039^{\mathrm{a}}$ \\
\hline M stage (M0 vs. M1) & 2.450 & $1.443-4.159$ & $0.011^{\mathrm{a}}$ & & & \\
\hline $\mathrm{N}$ stage (N0 vs. N1) & 1.724 & $1.441-2.189$ & $<0.001^{\mathrm{a}}$ & & & \\
\hline
\end{tabular}

${ }^{a} \mathrm{P}<0.05$. CI, confidence interval; HR, hazard ratio; lncRNA ROR1-AS1, long noncoding RNA tyrosine protein kinase transmembrane receptor 1 antisense RNA 1.

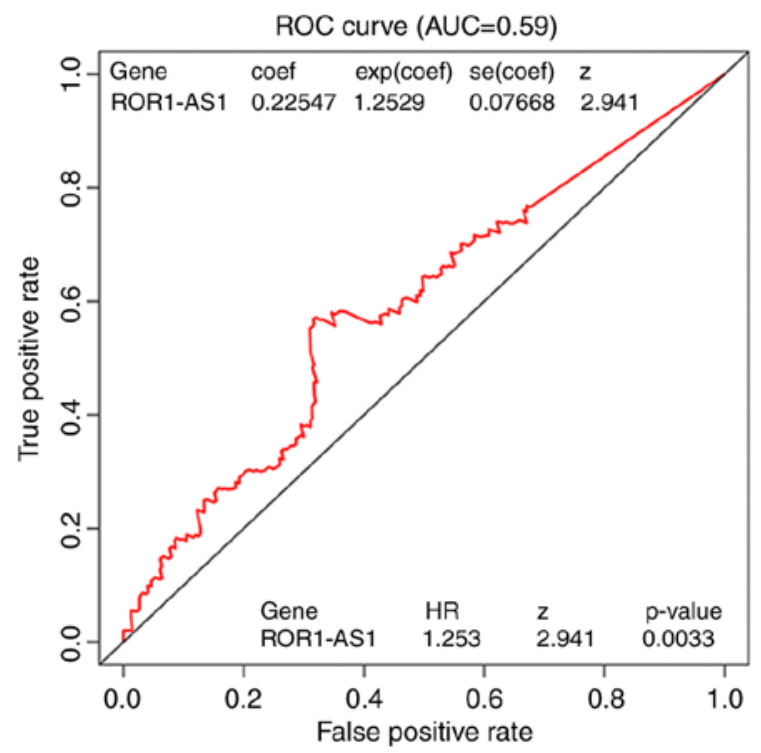

Figure 4. ROC curve to identify the optimal cutoff value for patients with hepatocellular carcinoma. ROR1-AS1, tyrosine protein kinase transmembrane receptor 1 antisense RNA; ROC, receiver operating characteristic; AUC, area under curve; $\mathrm{HR}$, hazard ratio.

composition of the 12 genome sets (Fig. S5). To find the most typical reference fragments, all GRCh38.95 loci present in the gene co-expression maps were deduced and merged, resulting in 12 reference donor fragments as settled in the outermost track. Subsequently, the number of gene co-expression maps containing each of these fragments were counted in the second track, excluding duplicate counts. In the inner sector, these pairs of gene sets showing co-expression relationships were linked. The sum of gene co-expression map alignments across the whole genome acted as the copy number profile for the 12 gene co-expression maps in the Circos plot (Fig. 10).

\section{Discussion}

LncRNAs can exhibit high or low expression in various cancers. LncRNAs can also acts as oncogenes, which interact with mRNAs and miRNAs to regulate cytological behavior and modulate cancer development (48). According to the present study, lncRNA ROR1-AS1 is important in HCC, and may serve as a biomarker for monitoring the prognosis of liver cancer. ROR1-AS1 expression in patients with HCC was analyzed, and it was found that ROR1-AS1 expression significantly varied based on clinical stage, $T$ stage, vital status and other factors.

Recently, considerable advances have been made regarding the function of ROR1-AS1, focusing on ROR1-AS1 upregulation in certain common digestive tumors $(12,13,49,50)$. Recent studies have reported the relation between ROR1-AS1 upregulation and cancers, such as MCL and colorectal cancer (11-13). According to the findings of the present study, ROR1-AS1 was highly expressed in HCC, consistent with other cancer studies $(12,13)$. ROR1-AS1 expression progressively increased from $\mathrm{T} 1$ to $\mathrm{T} 4$, and from clinical stage I to clinical stage IV, suggesting a role in the progression of HCC. Additionally, ROR1-AS1 expression was higher in patients that succumbed to HCC compared with those that survived, suggesting a link between ROR1-AS1 expression and patient survival.

Numerous previous studies have focused on the effects of ROR1-AS1 on the occurrence and growth of tumors $(12,13,51)$. Large-scale clinical statistics identified high expression of ROR1-AS1 during the growth process of liver cell lines $(52,53)$. In this study, it was suggested ROR1-AS1 may inform upon the diagnosis of tumors, as expression was associated with TNM classification. ROR1-AS1 exhibited a strong association with cancer prognosis; it was found that higher ROR1-AS1 expression was associated with poorer OS, particularly in males, patients aged $\leq 55$ years, and those with advanced T stage (T3/4), N0 stage and early pathological stage $(\mathrm{G} 1 / 2)$. Cox analysis demonstrated the independent prognostic effect of ROR1-AS1 on the OS of patients; therefore, it may serve as a useful biomarker for the prognosis of HCC. Studies have also shown that in addition to affecting common biological functions of tumor cells, the lncRNA ROR1-AS1 can also affect certain specific cytological behaviors, such as epithelial mesenchymal transition 
Table IV. LncRNA ROR1-AS1 high expression-associated GO terms and KEGG pathways in hepatocellular carcinoma.

A, KEGG pathways

\begin{tabular}{|c|c|c|c|c|}
\hline Term & Size & ES & NES & NOM P-value \\
\hline KEGG_ACUTE_MYELOID_LEUKEMIA & 57 & 0.32575217 & 1.174568 & 0.27732792 \\
\hline KEGG_ALLOGRAFT_REJECTION & 37 & 0.33567113 & 0.7853709 & 0.69214875 \\
\hline $\begin{array}{l}\text { KEGG_AMINO_SUGAR_AND_NUCLEOTIDE_ } \\
\text { SUGAR_METABOLISM }\end{array}$ & 44 & 0.21193676 & 0.7724282 & 0.7308448 \\
\hline KEGG_ARACHIDONIC_ACID_METABOLISM & 54 & 0.29082343 & 0.84411997 & 0.6816406 \\
\hline $\begin{array}{l}\text { KEGG_ARRHYTHMOGENIC_RIGHT_VENTRICULAR_ } \\
\text { CARDIOMYOPATHY_ARVC }\end{array}$ & 74 & 0.38242388 & 1.1008065 & 0.32595575 \\
\hline KEGG_ASTHMA & 30 & 0.4253977 & 1.035566 & 0.41453832 \\
\hline KEGG_AXON_GUIDANCE & 129 & 0.38427946 & 1.4202099 & 0.03307393 \\
\hline KEGG_BASAL_CELL_CARCINOMA & 55 & 0.47928926 & 1.3821044 & 0.058252428 \\
\hline KEGG_BLADDER_CANCER & 42 & 0.36261615 & 1.1552858 & 0.28235295 \\
\hline KEGG_CELL_ADHESION_MOLECULES_CAMS & 132 & 0.30416217 & 0.9411326 & 0.532 \\
\hline KEGG_CELL_CYCLE & 123 & 0.15106098 & 0.42698383 & 0.9573643 \\
\hline KEGG_CHEMOKINE_SIGNALING_PATHWAY & 186 & 0.39880365 & 1.3102372 & 0.14285715 \\
\hline KEGG_CHRONIC_MYELOID_LEUKEMIA & 73 & 0.30524614 & 1.1764947 & 0.2647059 \\
\hline KEGG_COLORECTAL_CANCER & 62 & 0.37809 & 1.325293 & 0.14285715 \\
\hline KEGG_COMPLEMENT_AND_COAGULATION_CASCADES & 68 & 0.30028233 & 0.8569669 & 0.6302187 \\
\hline KEGG_CYTOKINE_CYTOKINE_RECEPTOR_INTERACTION & 257 & 0.37159464 & 1.1011451 & 0.31853282 \\
\hline KEGG_DILATED_CARDIOMYOPATHY & 90 & 0.42610824 & 1.1813916 & 0.2446184 \\
\hline KEGG_DORSO_VENTRAL_AXIS_FORMATION & 24 & 0.2639202 & 0.7730944 & 0.8376238 \\
\hline KEGG_ECM_RECEPTOR_INTERACTION & 84 & 0.5676372 & 1.5391657 & 0.03420523 \\
\hline KEGG_ENDOCYTOSIS & 180 & 0.2655919 & 1.3141135 & 0.10337972 \\
\hline
\end{tabular}

$\mathrm{B}, \mathrm{GO}$ terms

\begin{tabular}{|c|c|c|c|c|}
\hline Term & Size & ES & NES & NOM P-value \\
\hline $\begin{array}{l}\text { GO_POSITIVE_REGULATION_OF_CANONICAL_WNT_ } \\
\text { SIGNALING_PATHWAY }\end{array}$ & 117 & 0.5034494 & 2.0831583 & 0 \\
\hline GO_CYTOSOLIC_RIBOSOME & 110 & 0.5240906 & 2.074979 & 0.006160164 \\
\hline GO_TRANSLATIONAL_INITIATION & 143 & 0.44866154 & 2.0731091 & 0.01002004 \\
\hline $\begin{array}{l}\text { GO_NUCLEAR_TRANSCRIBED_MRNA_CATABOLIC_ } \\
\text { PROCESS_NONSENSE_MEDIATED_DECAY }\end{array}$ & 118 & 0.45694864 & 2.0709035 & 0.004056795 \\
\hline $\begin{array}{l}\text { GO_REGULATION_OF_ESTABLISHMENT_OF_ } \\
\text { PLANAR_POLARITY }\end{array}$ & 108 & 0.4920704 & 2.0078113 & 0.002109705 \\
\hline GO_CYTOSOLIC_LARGE_RIBOSOMAL_SUBUNIT & 59 & 0.551799 & 1.9801823 & 0.003984064 \\
\hline $\begin{array}{l}\text { GO_ESTABLISHMENT_OF_PROTEIN_LOCALIZATION_ } \\
\text { TO_ENDOPLASMIC_RETICULUM }\end{array}$ & 104 & 0.500903 & 1.9766974 & 0.004024145 \\
\hline $\begin{array}{l}\text { GO_POSITIVE_REGULATION_OF_WNT_SIGNALING_ } \\
\text { PATHWAY }\end{array}$ & 149 & 0.4659426 & 1.9148449 & 0 \\
\hline GO_CELL_SUBSTRATE_JUNCTION & 396 & 0.4012108 & 1.8526521 & 0.009708738 \\
\hline GO_PROTEIN_TARGETING_TO_MEMBRANE & 156 & 0.33212492 & 1.8498257 & 0.021956088 \\
\hline GO_U1_SNRNP & 17 & 0.5754599 & 1.8482453 & 0.012244898 \\
\hline GO_CYTOSOLIC_SMALL_RIBOSOMAL_SUBUNIT & 43 & 0.5705049 & 1.8452722 & 0.007677543 \\
\hline GO_MULTI_ORGANISM_METABOLIC_PROCESS & 137 & 0.3726918 & 1.8385631 & 0.022821577 \\
\hline GO_NON_CANONICAL_WNT_SIGNALING_PATHWAY & 137 & 0.44534308 & 1.8334067 & 0 \\
\hline $\begin{array}{l}\text { GO_NEGATIVE_REGULATION_OF_EMBRYONIC_ } \\
\text { DEVELOPMENT }\end{array}$ & 25 & 0.7196995 & 1.8151437 & 0 \\
\hline GO_CYTOSOLIC_PART & 217 & 0.34144697 & 1.7857713 & 0.013461539 \\
\hline GO_NONMOTILE_PRIMARY_CILIUM_ASSEMBLY & 22 & 0.662353 & 1.7724643 & 0.002066116 \\
\hline GO_PROTEIN_KINASE_A_CATALYTIC_SUBUNIT_ & 15 & 0.642496 & 1.7654687 & 0.012 \\
\hline
\end{tabular}


Table IV. Continued.

\section{$\mathrm{B}, \mathrm{GO}$ terms}

\begin{tabular}{|c|c|c|c|c|}
\hline Term & Size & $\mathrm{ES}$ & NES & NOM P-value \\
\hline GO_INTEGRIN_BINDING & 105 & 0.56900364 & 1.7639837 & 0.002 \\
\hline GO_SIGNAL_TRANSDUCTION_IN_ABSENCE_OF_ & 32 & 0.51555276 & 1.7639508 & 0.004366812 \\
\hline
\end{tabular}

LIGAND

Enrichment biological functions were obtained from gene set enrichment analysis. LncRNA ROR1-AS1, long noncoding RNA tyrosine protein kinase transmembrane receptor 1 antisense RNA 1; GO, Gene Ontology; KEGG, Kyoto Encyclopedia of Genes and Genomes; ES, enrichment score; NES, normalized enrichment score; NOM P-value, Nominal P-value.

Table V. Altered gene expression in patients with high lncRNA ROR1-AS1 expression as determined via GSEA.

Expression change Gene names

Decreased expression

Increased expression

First increased then decreased

First decreased then increased
STK33, P53, CRX-NRL, SNF5, EIF4E, JNK, CRX, NRL, JAK2, PKCA, YAP1

EGFR, PIGF, TBK1, LTE2, ESC, LEF1, ERB2, MEK, GLI1, TGFB, RAF, PRC2, AKT,

BCAT, E2F3, Cyclin D1, GCNP

RAF, mTOR, ATF2, LET1, E2F1, CSR, VEGF, IL2, SRC, MYC, MEK, IL15, PDGF, TGFB, WNT

P53, KRAS, HOXA9, RB, BMI1, MEL18, RPS14, PTEN, SNF5, ALK, NRL, ERLA, CTIP

LncRNA ROR1-AS1, long noncoding RNA tyrosine protein kinase transmembrane receptor 1 antisense RNA 1; GSEA, gene set enrichment analysis.

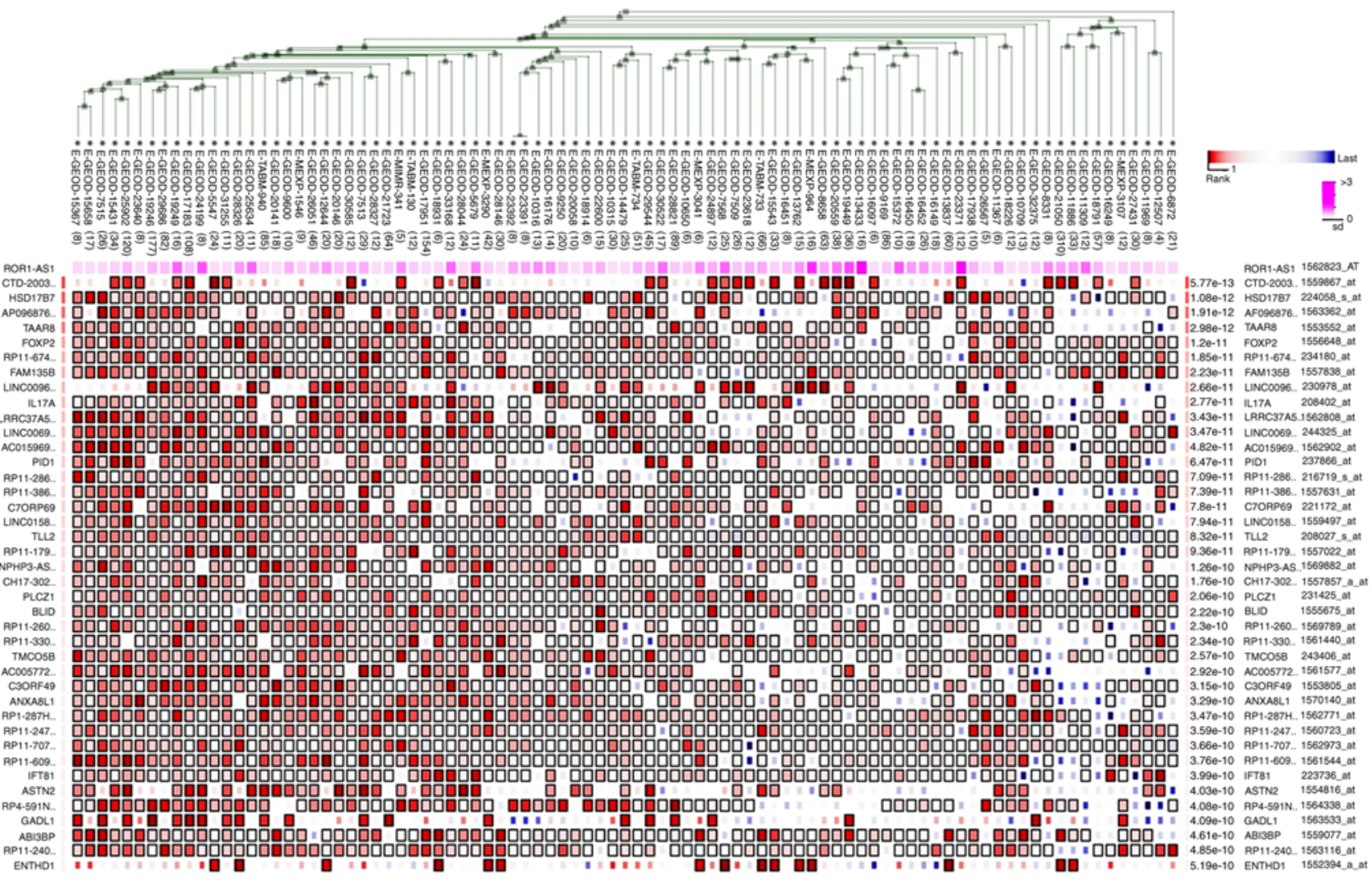

Figure 5. Co-expressed genes predicted by MEM. Genes that were co-expressed with ROR1-AS1 were identified using MEM, and the potential mutually regulatory genes interacting with ROR1-AS1 in hepatocellular carcinoma were investigated. ROR1-AS1, tyrosine protein kinase transmembrane receptor 1 antisense RNA; MEM, Multi Experiment Matrix. 

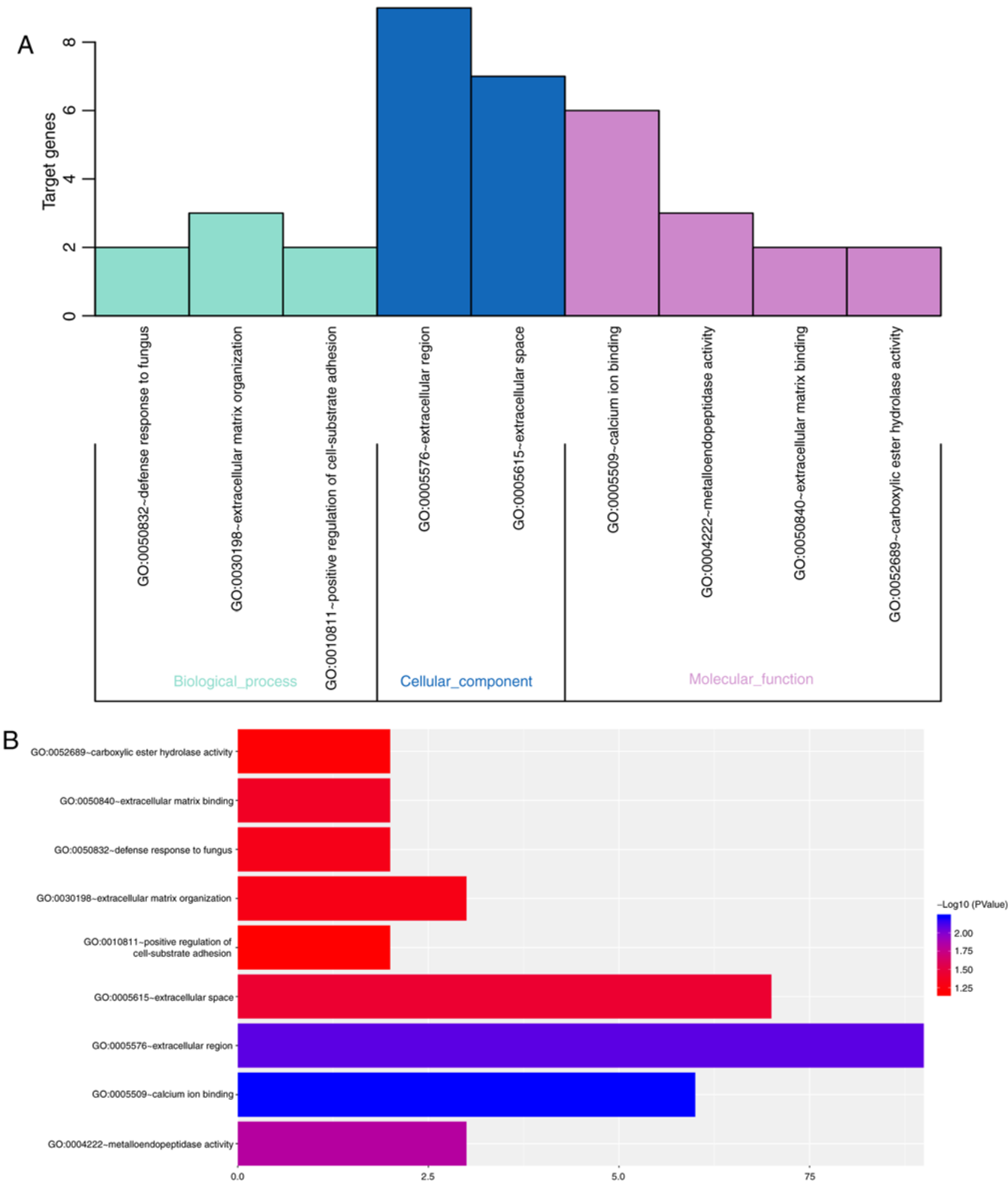

Figure 6. Significantly enriched GO terms identified by DAVID. Cytoscape and R were used to conduct visual enrichment analysis of genes enriched in GO terms and construct an interaction network for related genes. (A and B) Significant GO terms identified by DAVID.

and cell proliferation $(12,13,51)$. After functional enrichment analysis of ROR1-AS1, it was found that ROR1-AS1 exhibited a very close relationship with cytosolic ribosomes, cell substrate junctions, integrin binding, positive regulation of Wnt signaling pathway, regulation of establishment of planar polarity, negative regulation of development, nonmotile primary cilium assembly, protein kinase A catalytic subunit binding and signal transduction in absence of ligand.
To explore the biological role of lncRNA ROR1-AS1 in HCC in depth, MEM was used. In total, $>50$ genes were indicated to be closely associated with ROR1-AS1. First, the functional protein association network indicated that there may be certain small regulatory sub-networks in the whole network, suggesting that is a hierarchy of regulatory networks involved in ROR1-AS1. After functional enrichment of co-expressed genes with GO and KEGG, these genes were found to be enriched in 

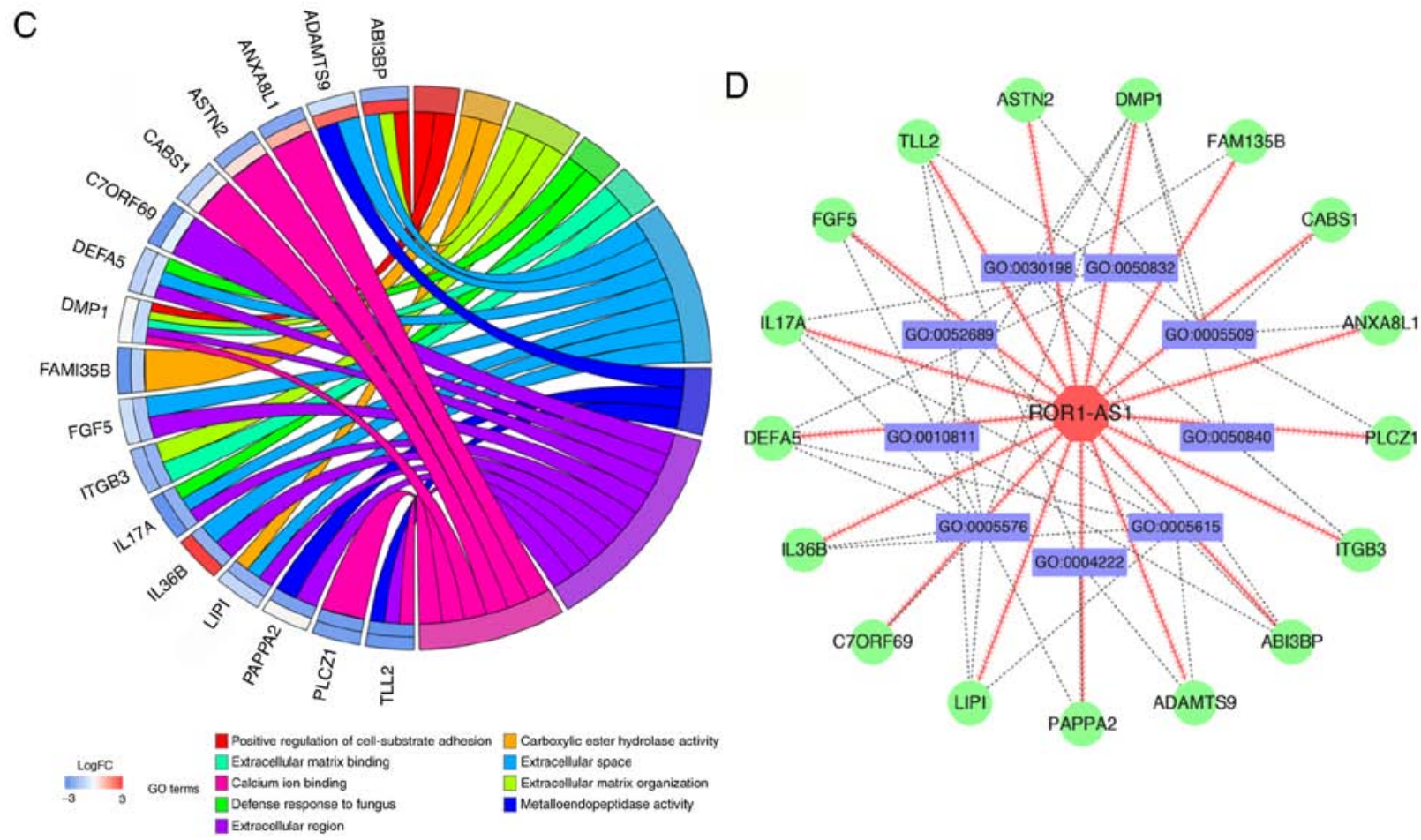

Figure 6. Continued. Significantly enriched GO terms identified by DAVID. (C and D) Of the 40 results predicted by MEM (Fig. 5), 17 genes were enriched in the significant GO terms. MEM, Multi Experiment Matrix; GO, Gene Ontology; DAVID, Database for Annotation, Visualization and Integrated Discovery.

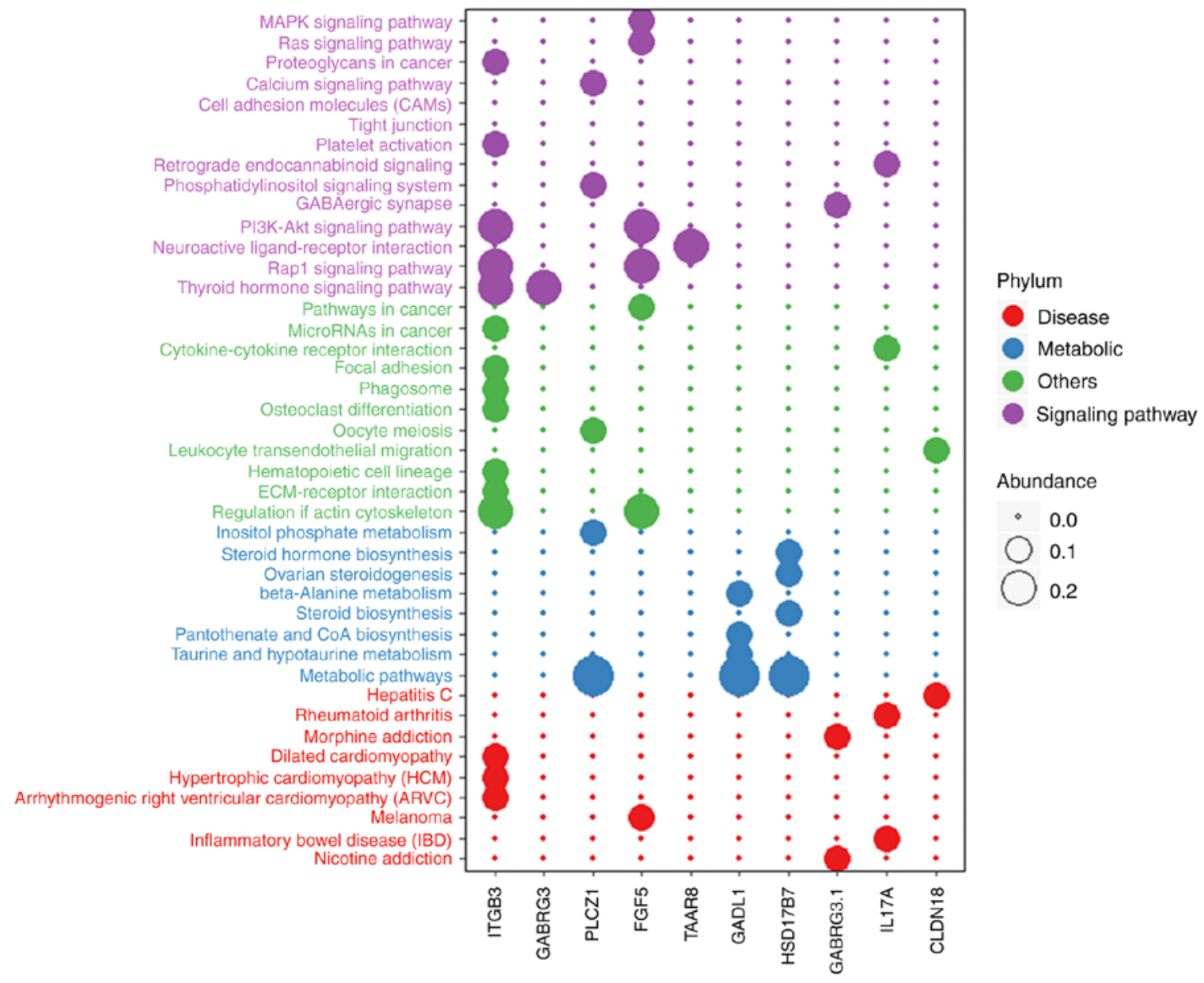

Figure 7. Significantly enriched KEGG pathways identified by KOBAS. Using the 40 genes predicted by MEM, 42 different KEGG pathways were identified as enriched by KOBAS. These signaling pathways can be roughly divided into four broad categories, of which 10 genes and 6 signaling pathways were most strongly associated. KEGG, Kyoto Encyclopedia of Genes and Genomes; KOBAS, KO-Based Annotation System; MEM, Multi Experiment Matrix. 
Table VI. LncRNA ROR1-AS1-associated GO terms and KEGG pathways in hepatocellular carcinoma.

\begin{tabular}{lcccll}
\hline ID & $\begin{array}{c}\text { Percentage } \\
\text { enrichment }(\%)\end{array}$ & R-value & P-value & FDR & \multicolumn{1}{c}{ Term/pathway } \\
\hline GO:0005509 & 10.52631579 & N/A & 0.005942049 & 6.078863585 & Calcium ion binding \\
GO:0005576 & 15.78947368 & N/A & 0.008242573 & 8.138546109 & Extracellular region \\
GO:0004222 & 5.263157895 & N/A & 0.014987253 & 14.69223656 & Metalloendopeptidase activity \\
GO:0005615 & 12.28070175 & N/A & 0.036377209 & 31.61735184 & Extracellular space \\
GO:0050840 & 3.50877193 & N/A & 0.042273690 & 36.52490946 & Extracellular matrix binding \\
GO:0050832 & 3.50877193 & N/A & 0.048703923 & 45.96726280 & Defense response to fungus \\
hsa04919 & N/A & 0.218307346 & 0.012053686 & N/A & Thyroid hormone signaling pathway \\
hsa04015 & N/A & 0.218307346 & 0.035140101 & N/A & Rap1 signaling pathway \\
hsa04810 & N/A & 0.218307346 & 0.036348782 & N/A & Regulation of actin cytoskeleton \\
hsa04151 & N/A & 0.218307346 & 0.038191424 & N/A & PI3K-Akt signaling pathway \\
hsa04080 & N/A & 0.218307346 & 0.045736192 & N/A & Neuroactive ligand-receptor interaction \\
hsa01100 & N/A & 0.281923180 & 0.047118941 & N/A & Metabolic pathways LncRNAROR1-AS1, \\
& & & & & long noncoding \\
\hline
\end{tabular}

RNA tyrosine protein kinase transmembrane receptor 1 antisense RNA 1GO, Gene Ontology; KEGG, Kyoto Encyclopedia of Genes and Genomes; FDR, false discovery rate.

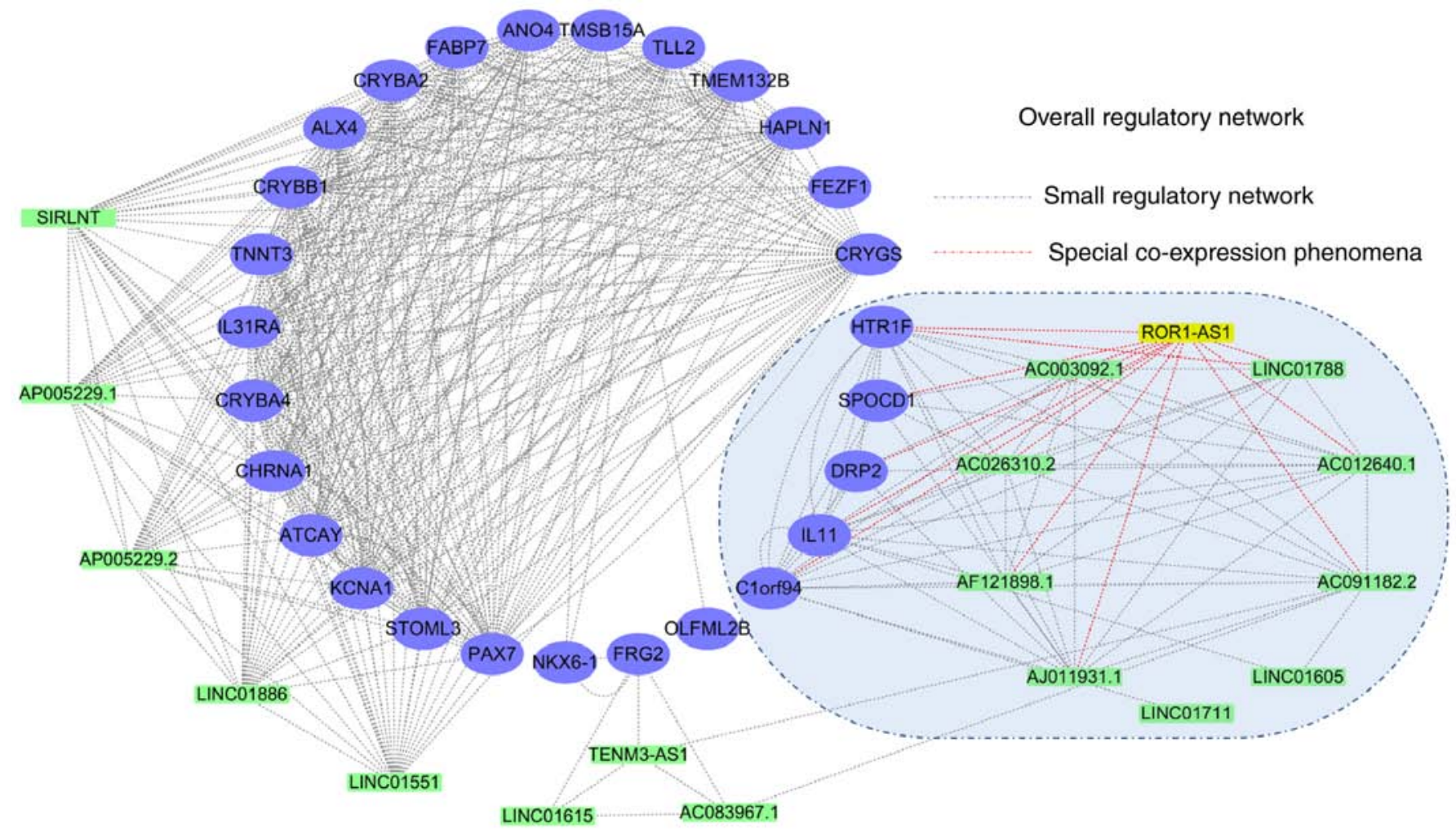

Figure 8. Predicted co-expression network of ROR1-AS1. Cytoscape was used to identify a potential co-expressed regulatory network; with the genes exhibiting co-expression relationships, a large regulatory network containing 45 genes and a small regulatory network containing 15 genes was identified. Additionally, 10 pairs of genes exhibiting direct regulatory interactions with ROR1-AS1 were marked with red lines. ROR1-AS1, tyrosine protein kinase transmembrane receptor 1 antisense RNA.

the following biological processes and compartments: Calcium ion binding, metalloendopeptidase activity, extracellular matrix binding and defense response to fungus, and the extracellular region and extracellular space. Additionally, KEGG analysis revealed that ROR1-AS1 and co-expressed genes were associated with the thyroid hormone, Rap1 and PI3K-Akt signaling pathways, regulation of the actin cytoskeleton, neuroactive ligand-receptor interactions and metabolic pathways. 


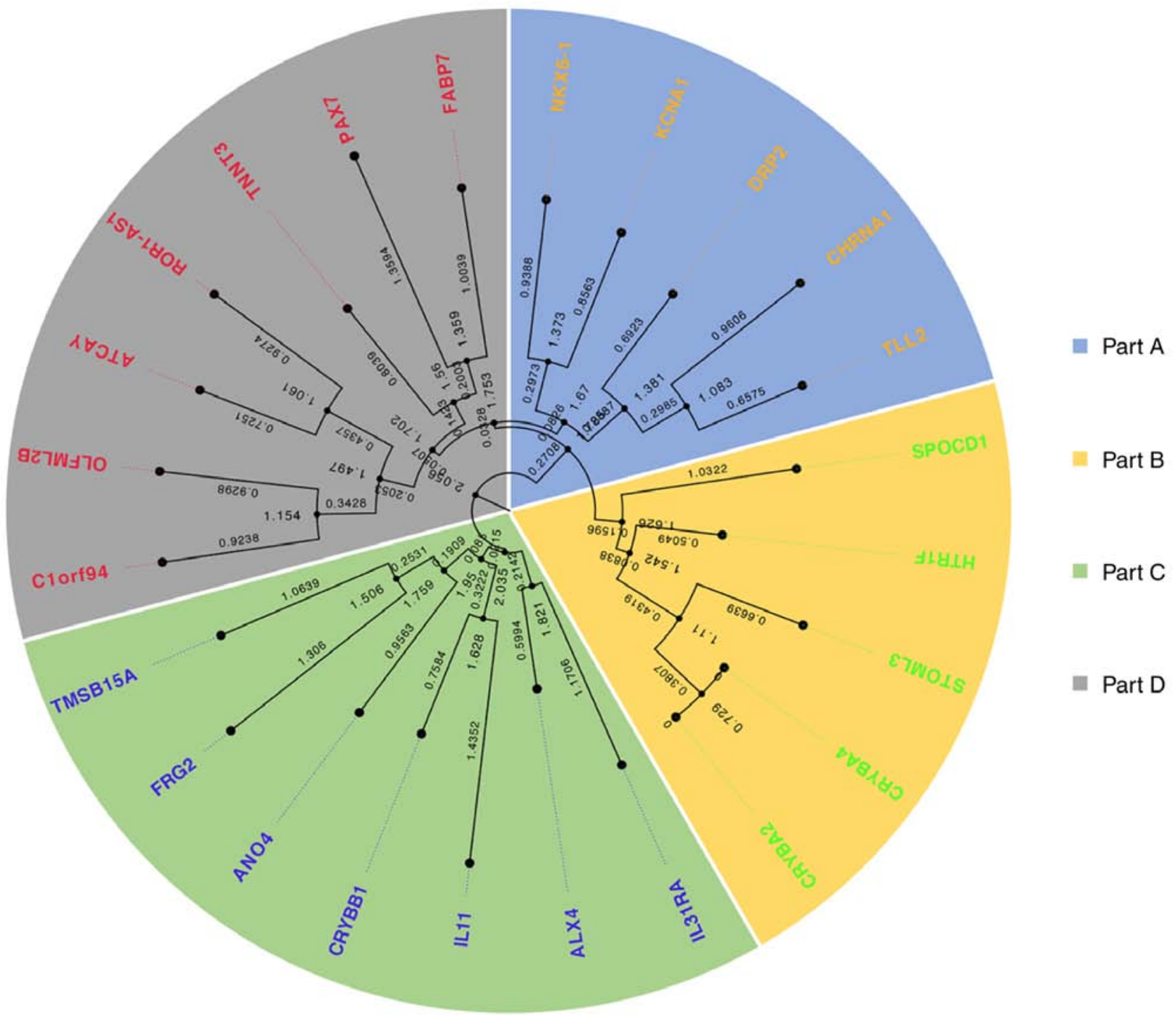

Figure 9. Neighbor-joining phylogeny for the selected clade of long noncoding RNA ROR1-AS1. Phylogenetic tree containing 24 genes for which clear transcribed sequences in the NCBI and NONCODE databases could be found was generated. The value on the branch is the genetic distance between different genes. ROR1-AS1, tyrosine protein kinase transmembrane receptor 1 antisense RNA.

To further analyze the important biological role of ROR1-AS1 in HCC, co-expression analysis was conducted using data obtained from GSE54236. Then, a comprehensive analysis was conducted using the co-expressed genes of ROR1-AS1 identified in GSE54236. WGCNA analysis identified a potential co-expression regulatory network, suggesting that within these co-expressed genes, there may be a large regulatory network comprising 45 genes and a small regulatory network comprising 15 genes. It is noteworthy that 10 genes exhibited direct regulatory interactions with ROR1-AS1. Using the NCBI and NONCODE databases, spatial structures and transcript information for these genes included in the large regulatory network were obtained. A phylogenetic tree was constructed using 23 genes collected from the NCBI and NONCODE databases which possessed clear transcript information from homo sapiens. The phylogenetic tree showed that the co-expressed genes were split into 4 subfamilies; Clorf94, OLFML2B, ATCAY, TNNT3, PAX7 and FABP7 were in the same subfamily as ROR1-AS1.
The integration of data from MEM, GEO and TCGA enabled exclusion of genes with $\mathrm{R}<0.5$, and 12 genes with $\mathrm{R}>0.5$ were maintained and verified in the three databases. The number of co-expressed gene pairs was obtained, including the aforementioned 12 genes of different types (lncRNAs and mRNAs). Finally, these data were combined with gene expression data to predict possible co-expression regulatory networks. GRCh38.95 helped to perform whole-genome mapping, covering the 12 genes that exhibited the strongest regulatory relationships with ROR1-AS1 in HCC. Therefore, the co-expression regulatory network can be seen directly without relying on complex algorithmic methods that rely on complex assumptions.

Based on existing literature, the present study is the first, to our knowledge, to report a potential role for lncRNA ROR1-AS1 in the prognosis of HCC. However, to ensure the wide application of ROR1-AS1 in evaluating the prognosis of liver cancer, future clinical studies should be conducted to verify these conclusions. 


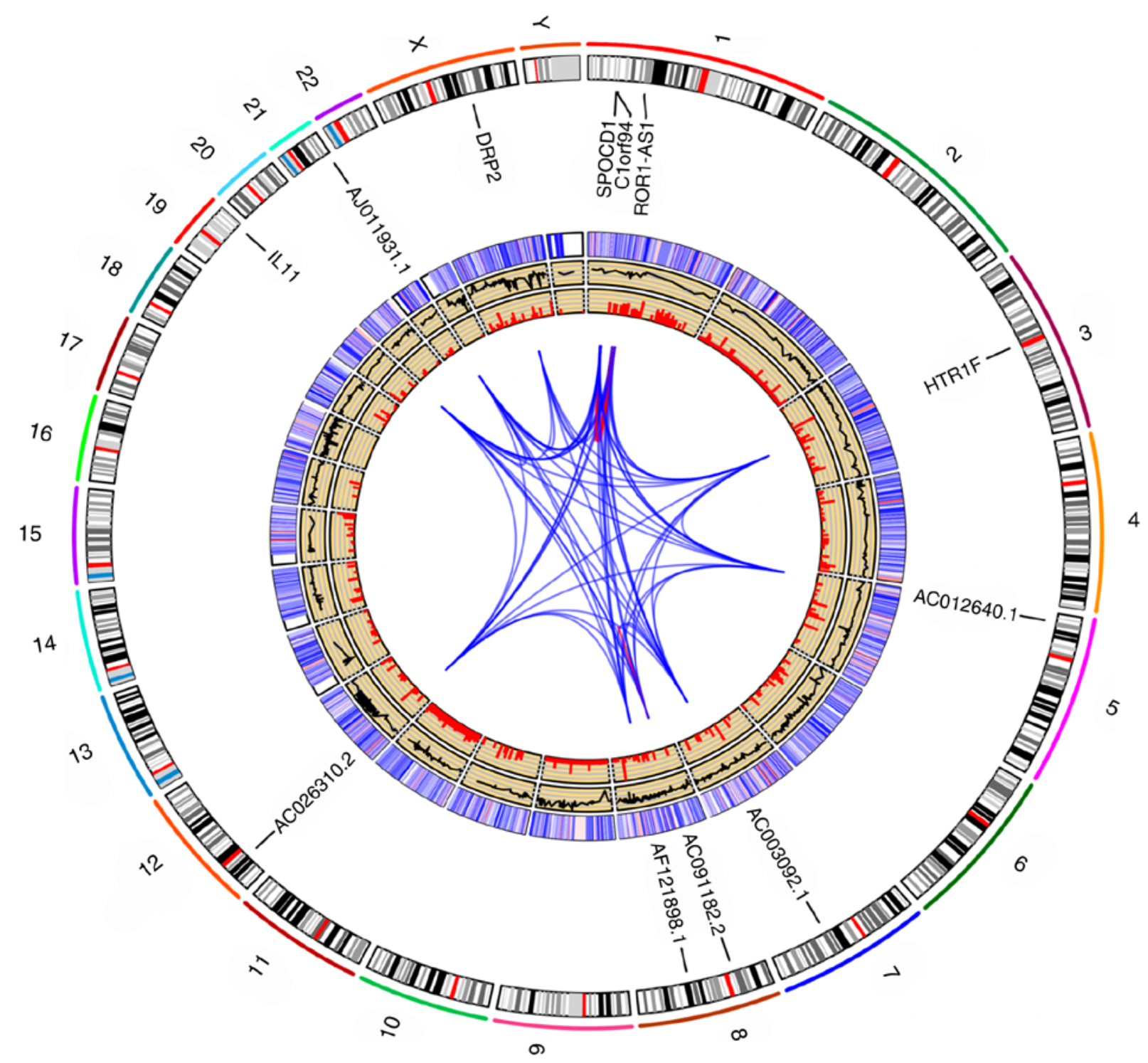

Figure 10. Circos plot derived from genes identified by the integration of three databases. Linked lines in the middle of the Circos plots show co-expression of different genes. The next two tracks show the expression levels of different genes. The outermost track shows the chromosome information of these genes. Plots were generated using the Circos visualization tool by R. ROR1-AS1, tyrosine protein kinase transmembrane receptor 1 antisense RNA.

The present found that expression of lncRNA ROR1-AS1 was significantly increased in HCC patients and associated with several clinical features and an undesirable prognosis; therefore, IncRNA ROR1-AS1 may serve as a useful biomarker for the prognosis of patients with HCC.

\section{Acknowledgements}

Not applicable.

\section{Funding}

This study was supported by the Key Science and Technology R\&D Project of Jilin Science and Technology Department, no. 20180201055YY (Sponsor: Meng ZH).

\section{Availability of data and materials}

The datasets generated and/or analyzed during the current study are available in the TCGA (https://portal.gdc. cancer.gov/), GEO (https://www.ncbi.nlm.nih.gov/geo/ download/?acc=GSE54236) and MEM (http://biit.cs.ut.ee/ $\mathrm{mem} /$ ) repositories.

\section{Authors' contributions}

ZZ, YHL and ZHM participated in the design and conception of the study, the collection of data and drafting of the manuscript. ZZ and SQW performed statistical analyses. ZZ and YF participated in the interpretation of data. YHL and ZHM revised the manuscript critically. All authors read and approved the final manuscript.

\section{Ethics approval and consent to participate}

Not applicable.

\section{Patient consent for publication}

Not applicable. 


\section{Competing interests}

The authors declare that there are no competing interests.

\section{References}

1. Hartke J, Johnson M and Ghabril M: The diagnosis and treatment of hepatocellular carcinoma. Semin Diagn Pathol 34: 153-159, 2017.

2. Ranganathan S,Lopez-Terrada D and Alaggio R: Hepatoblastoma and pediatric hepatocellular carcinoma: An update. Pediatr Dev Pathol: Sep 25, 2019 (Epub ahead of print).

3. Fang Q, Xie QS, Chen JM, Shan SL, Xie K, Geng XP and Liu FB Long-term outcomes after hepatectomy of huge hepatocellular carcinoma: A single-center experience in China. Hepatobiliary Pancreat Dis Int: Sep 11, 2019 (Epub ahead of prin).

4. Arendt BM, Teterina A, Pettinelli P, Comelli EM, Ma DWL, Fung SK, McGilvray ID, Fischer SE and Allard JP: Cancerrelated gene expression is associated with disease severity and modifiable lifestyle factors in non-alcoholic fatty liver disease. Nutrition 62: 100-107, 2019.

5. Ma YC, Yang JY and Yan LN: Relevant markers of cancer stem cells indicate a poor prognosis in hepatocellular carcinoma patients: A meta-analysis. Eur J Gastroenterol Hepatol 25: 1007-1016, 2013

6. Shiani A, Narayanan S, Pena L and Friedman M: The role of diagnosis and treatment of underlying liver disease for the prognosis of primary liver cancer. Cancer Control 24: 1073274817729240,2017

7. Yin Z, Dong C, Jiang K, Xu Z, Li R, Guo K, Shao S and Wang L: Heterogeneity of cancer-associated fibroblasts and roles in the progression, prognosis, and therapy of hepatocellular carcinoma. J Hematol Oncol 12: 101, 2019.

8. Pang B, Wang Q, Ning S, Wu J, Zhang X, Chen Y and Xu S: Landscape of tumor suppressor long noncoding RNAs in breas cancer. J Exp Clin Cancer Res 38: 79, 2019.

9. Zhang Z, Liu F, Yang F and Liu Y: Kockdown of OIP5-AS1 expression inhibits proliferation, metastasis and EMT progress in hepatoblastoma cells through up-regulating miR-186a-5p and down-regulating ZEB1. Biomed Pharmacother 101: 14-23, 2018.

10. Zhu X, Liu Y, Yu J, Du J, Guo R, Feng Y, Zhong G, Jiang Y and Lin J: LncRNA HOXA-AS2 represses endothelium inflammation by regulating the activity of NF- $\mathrm{B}$ signaling. Atherosclerosis 281: 38-46, 2019.

11. Hu G, Gupta SK, Troska TP, Nair A and Gupta M: Long non-coding RNA profile in mantle cell lymphoma identifies a functional lncRNA ROR1-AS1 associated with EZH2/PRC2 complex. Oncotarget 8: 80223-80234, 2017.

12. Wang FZ, Zhang MQ, Zhang L and Zhang MC: Long non-coding RNA ROR1-AS1 enhances colorectal cancer metastasis by targeting miR-375. Eur Rev Med Pharmacol Sci 23: 6899-6905, 2019.

13. Liao T, Maierdan SL and Lv C: ROR1-AS1 promotes tumorigenesis of colorectal cancer via targeting Wnt $/ \beta$-catenin. Eur Rev Med Pharmacol Sci 23 (3 Suppl): S217-S223, 2019.

14. Samur MK: RTCGAToolbox: A new tool for exporting TCGA Firehose data. PLoS One 9: e106397, 2014

15. R Core Team: R: A language and environment for statistical computing. R Foundation for Statistical Computing, Vienna, 2013

16. Villa E Critelli R, Lei B, Marzocchi G, Camma C, Giannelli G, Pontisso P, Cabibbo G, Enea M, Colopi S, et al: Neoangiogenesis-related genes are hallmarks of fast-growing hepatocellular carcinomas and worst survival. Results from a prospective study. Gut 65: 861-869, 2016.

17. Zubiete-Franco I, Garcia-Rodriguez JL, Lopitz-Otsoa F, Serrano-Macia M, Simon J, Fernandez-Tussy P, Barbier-Torres L, Fernandez-Ramos D, Gutierrez-de-Juan V, Lopez de Davalillo S, et al: SUMOylation regulates LKB1 localization and its oncogenic activity in liver cancer. EBioMedicine 40: 406-421, 2019

18. Jiao Y, Fu Z, Li Y, Meng L and Liu Y: High EIF2B5 mRNA expression and its prognostic significance in liver cancer: $A$ study based on the TCGA and GEO database. Cancer Manag Res 10: 6003-6014, 2018.

19. Ginestet C: ggplot2: Elegant Graphics for Data Analysis. J Royal Statistic Soc Series A 174: 245-245, 2011.

20. Mitteer DR, Greer BD, Fisher WW and Cohrs VL: Teaching behavior technicians to create publication-quality, single-case design graphs in graphpad prism 7. J Appl Behav Anal 51: 998-1010, 2018.
21. Schober P, Boer C and Schwarte LA: Correlation Coefficients: Appropriate Use and Interpretation. Anesth Analg 126: 1763-1768, 2018

22. Kourou K, Exarchos TP, Exarchos KP, Karamouzis MV and Fotiadis DI: Machine learning applications in cancer prognosis and prediction. Comput Struct Biotechnol J 13: 8-17, 2015.

23. Lin H and Zelterman D: Modeling Survival Data: Extending the Cox Model. Technometrics 44: 85-86, 2002.

24. Robin X, Turck N, Hainard A, Tiberti N, Lisacek F, Sanchez JC and Muller M: pROC: An open-source package for $\mathrm{R}$ and $\mathrm{S}+$ to analyze and compare ROC curves. BMC Bioinformatics 12: 77, 2011.

25. Li N, Zhao L, Guo C, Liu C and Liu Y: Identification of a novel DNA repair-related prognostic signature predicting survival of patients with hepatocellular carcinoma. Cancer Manag Res 11: 7473-7484, 2019.

26. Mootha VK, Lindgren CM, Eriksson KF, Subramanian A, Sihag S, Lehar J, Puigserver P, Carlsson E, Ridderstrale M, Laurila E, et al: PGC-1alpha-responsive genes involved in oxidative phosphorylation are coordinately downregulated in human diabetes. Nat Genet 34: 267-273, 2003.

27. Subramanian A, Tamayo P, Mootha VK, Mukherjee S, Ebert BL, Gillette MA, Paulovich A, Pomeroy SL, Golub TR, Lander ES and Mesirov JP: Gene set enrichment analysis: A knowledge-based approach for interpreting genome-wide expression profiles. Proc Natl Acad Sci USA 102: 15545-15550, 2005.

28. Huang da W, Sherman BT and Lempicki RA: Systematic and integrative analysis of large gene lists using DAVID bioinformatics resources. Nat Protoc 4: 44-57, 2009.

29. Ashburner M, Ball CA, Blake JA, Botstein D, Butler H, Cherry JM, Davis AP, Dolinski K, Dwight SS, Eppig JT, et al: Gene ontology: Tool for the unification of biology. The Gene Ontology Consortium. Nat Genet 25: 25-29, 2000.

30. The Gene Ontology C: The Gene Ontology Resource: 20 years and still GOing strong. Nucleic Acids Res 47: D330-D338, 2019.

31. Kanehisa M and Goto S: KEGG: Kyoto encyclopedia of genes and genomes. Nucleic Acids Res 28: 27-30, 2000.

32. Kanehisa M, Sato Y, Furumichi M, Morishima K and Tanabe M: New approach for understanding genome variations in KEGG. Nucleic Acids Res 47: D590-D595, 2019.

33. Kanehisa M: Toward understanding the origin and evolution of cellular organisms. Protein Sci 28: 1947-1951, 2019.

34. Zhang B and Horvath S: A general framework for weighted gene co-expression network analysis. Stat Appl Genet Mol Biol 4: Article 17, 2005

35. Deng Y, He RQ, Zhang R, Gan BL, Zhang Y, Chen G and $\mathrm{Hu} \mathrm{XH}$ : The expression of HOXA13 in lung adenocarcinoma and its clinical significance: A study based on The Cancer Genome Atlas, Oncomine and reverse transcription-quantitative polymerase chain reaction. Oncol Lett 15: 8556-8572, 2018.

36. He RQ, Xiong DD, Ma J, Hu XH, Chen G and Sun WL: The clinicopathological significance and correlative signaling pathways of an autophagy-related gene, ambral, in breast cancer: A study of 25 microarray RNA-Seq datasets and in-house gene silencing. Cell Physiol Biochem 51: 1027-1040, 2018

37. Chan EKF, Cameron DL, Petersen DC, Lyons RJ, Baldi BF, Papenfuss AT, Thomas DM and Hayes VM: Optical mapping reveals a higher level of genomic architecture of chained fusions in cancer. Genome Res 28: 726-738, 2018.

38. Dean CB and Nielsen JD: Generalized linear mixed models: A review and some extensions. Lifetime Data Anal 13: 497-512, 2007.

39. Pei G, Chen L and Zhang W: WGCNA application to proteomic and metabolomic data analysis. Methods Enzymol 585: 135-158, 2017.

40. Winden KD, Oldham MC, Mirnics K, Ebert PJ, Swan $\mathrm{CH}$, Levitt P, Rubenstein JL, Horvath S and Geschwind DH: The organization of the transcriptional network in specific neuronal classes. Mol Syst Biol 5: 291, 2009.

41. Yang J, Yu H, Liu BH, Zhao Z, Liu L, Ma LX, Li YX and Li YY: DCGL v2.0: An R package for unveiling differential regulation from differential co-expression. PLoS One 8: e79729, 2013.

42. Ravasz E, Somera AL, Mongru DA, Oltvai ZN and Barabasi AL Hierarchical organization of modularity in metabolic networks. Science 297: 1551-1555, 2002.

43. Hameed MS, Wang Z, Vasseur L and Yang G: Molecular characterization and the function of argonaute 3 in RNAi pathway of plutella xylostella. Int J Mol Sci 19: pii: E1249, 2018.

44. Hall BG: Building phylogenetic trees from molecular data with MEGA. Mol Biol Evol 30: 1229-1235, 2013.

45. Kumar S, Stecher G and Tamura K: MEGA7: Molecular evolutionary genetics analysis version 7.0 for bigger datasets. Mol Biol Evol 33: 1870-1874, 2016. 
46. Porcella SF, Carlson JH, Sturdevant DE, Sturdevant GL, Kanakabandi K, Virtaneva K, Wilder H, Whitmire WM, Song L and Caldwell HD: Transcriptional profiling of human epithelial cells infected with plasmid-bearing and plasmid-deficient Chlamydia trachomatis. Infect Immun 83: 534-543, 2015.

47. Kumar R, Sobhy H, Stenberg P and Lizana L: Genome contact map explorer: A platform for the comparison, interactive visualization and analysis of genome contact maps. Nucleic Acids Res 45: e152, 2017.

48. Choi S, Lee S, Kim Y, Hwang H and Park T: HisCoM-GGI: Hierarchical structural component analysis of gene-gene interactions. J Bioinform Comput Biol 16: 1840026, 2018.

49. Pekarsky $Y$ and Croce CM: Noncoding RNA genes in cancer pathogenesis. Adv Biol Regul 71: 219-223, 2019.

50. Cetin M, Odabas G, Douglas LR, Duriez PJ, Balcik-Ercin P, Yalim-Camci I, Sayan AE and Yagci T: ROR1 expression and its functional significance in hepatocellular carcinoma cells. Cells 8: E210, 2019.
51. Xu C, Aragam N, Li X, Villla EC, Wang L, Briones D, Petty L, Posada Y, Arana TB, Cruz G, et al: BCL9 and C9orf5 are associated with negative symptoms in schizophrenia: Meta-analysis of two genome-wide association studies. PLoS One 8: e51674, 2013.

52. Rose JE, Behm FM, Drgon T, Johnson C and Uhl GR: Personalized smoking cessation: Interactions between nicotine dose, dependence and quit-success genotype score. Mol Med 16: 247-253, 2010.

53. Kabir MH, Patrick R, Ho JWK and O'Connor MD: Identification of active signaling pathways by integrating gene expression and protein interaction data. BMC Syst Biol 12 (Suppl 9): S120, 2018.

(i) $(9)$ This work is licensed under a Creative Commons EY AC No Attribution-NonCommercial-NoDerivatives 4.0 International (CC BY-NC-ND 4.0) License. 